\title{
Characterizing the spatial variations and correlations of large rainstorms for landslide study
}

\author{
Liang Gao, Limin Zhang, and Mengqian Lu \\ Department of Civil and Environmental Engineering, The Hong Kong University of Science and Technology, \\ Clear Water Bay, Hong Kong \\ Correspondence to: Limin Zhang (cezhangl@ust.hk)
}

Received: 1 March 2017 - Discussion started: 30 March 2017

Revised: 20 July 2017 - Accepted: 1 August 2017 - Published: 13 September 2017

\begin{abstract}
Rainfall is the primary trigger of landslides in Hong Kong; hence, rainstorm spatial distribution is an important piece of information in landslide hazard analysis. The primary objective of this paper is to quantify spatial correlation characteristics of three landslide-triggering large storms in Hong Kong. The spatial maximum rolling rainfall is represented by a rotated ellipsoid trend surface and a random field of residuals. The maximum rolling $4,12,24$, and $36 \mathrm{~h}$ rainfall amounts of these storms are assessed via surface trend fitting, and the spatial correlation of the detrended residuals is determined through studying the scales of fluctuation along eight directions. The principal directions of the surface trend are between 19 and $43^{\circ}$, and the major and minor axis lengths are 83-386 and 55-79 km, respectively. The scales of fluctuation of the residuals are found between 5 and $30 \mathrm{~km}$. The spatial distribution parameters for the three large rainstorms are found to be similar to those for four ordinary rainfall events. The proposed rainfall spatial distribution model and parameters help define the impact area, rainfall intensity and local topographic effects for landslide hazard evaluation in the future.
\end{abstract}

\section{Introduction}

Severe rainstorms are one of the most dangerous meteorological phenomena which pose risks to human lives and properties. A large rainstorm may cause serious damage to infrastructure and threaten public safety. For instance, a large storm hit Lantau Island, Hong Kong, on 5-7 June 2008 and caused about 2400 natural terrain landslides and 622 flooding spots (CEDD, 2009). Historical records show that the spatial rainstorm variation and the potential for triggering landslides are closely correlated. The Geotechnical Engineering Office (GEO) maintains a Natural Terrain Landslide Inventory (NTLI; King, 1999; Maunsell-Fugro Joint Venture, 2007), which has records of 19763 natural terrain landslides and debris flows up to 2013 as well as 89571 relict natural terrain landslides. The data of natural terrain landslides that occurred on 5-7 June 2008 are extracted and the distributions of the landslide volume and the maximum $24 \mathrm{~h}$ rolling rainfall are plotted in Fig. 1. There is a close correspondence between the observed landslide volume and the maximum $24 \mathrm{~h}$ rolling rainfall in space. Characterizing the spatial characteristics of storms is therefore essential for assessing rain-induced landslide hazards.

Numerical analyses have also been conducted to establish the relation between rainfall characteristics and landslides (e.g., Gao et al., 2016, 2017). Geotechnical and environmental factors, such as slope gradient, rock and soil formations, groundwater conditions, vegetation, and the presence of civil infrastructure, are believed to ultimately affect the triggering of landslides in addition to rainfall intensity. The main factors that affect triggering of natural terrain landslides are summarized in Fig. 2.

In hazards mitigation and engineering design, certain "design storms" must be considered, and the engineering system should be sufficiently safe under such design storms (Gao et al., 2017). A design storm is often defined by a hyetograph (time distribution) and an isohyet (spatial distribution). For a particular region where the spatial rainfall variation is significant, a uniform representation of the spatial distribution is not reasonable since a storm has a centre and influences a limited area (AECOM and Lin, 2015). Instead, rel- 


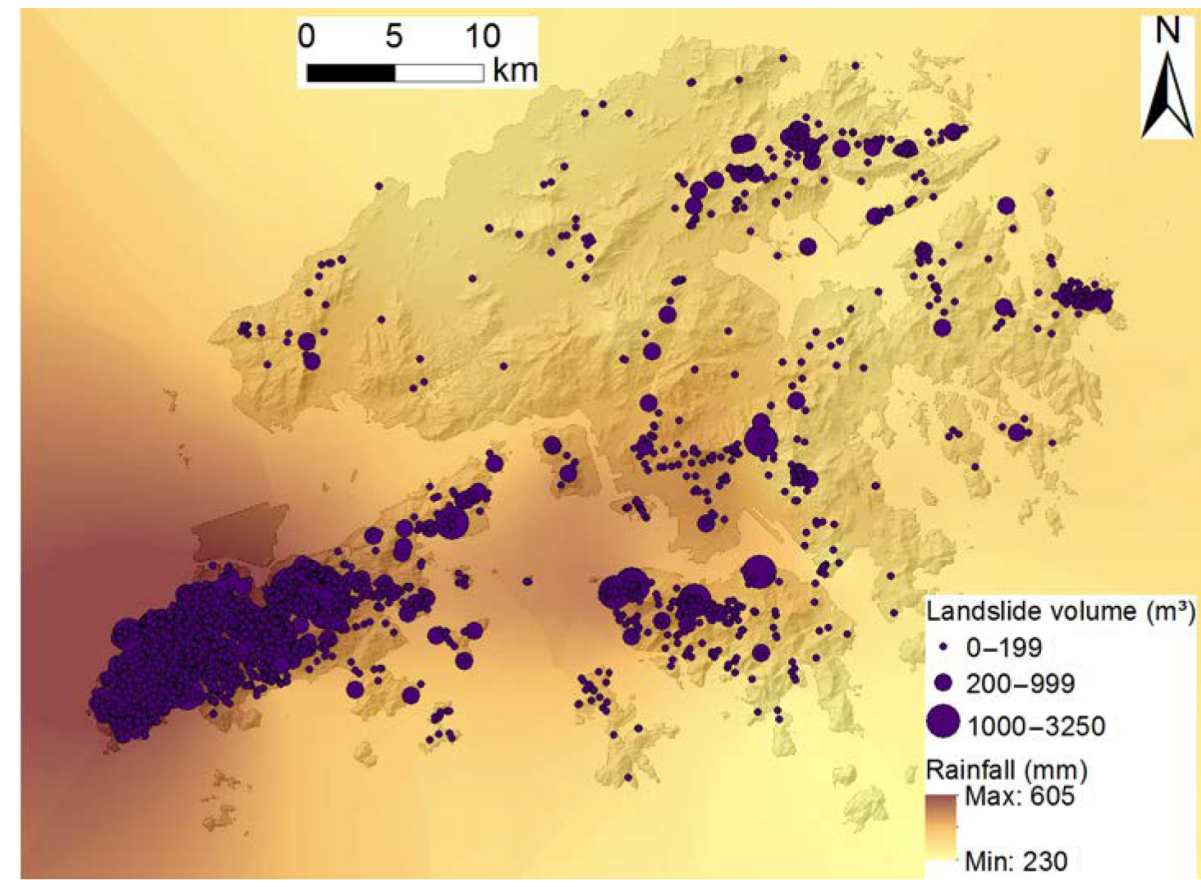

Figure 1. Spatial distributions of the maximum $24 \mathrm{~h}$ rolling rainfall and the landslides triggered in Hong Kong on 5-7 June 2008.

evant spatial variation factors of rainfall must be characterized, such as the geometry of spatial form (agglomerate and local gradient) and the spatial correlation.

A storm is difficult to model due to its intermittence (i.e., no rainfall at a particular position during a particular short period) and strong spatial and temporal heterogeneity (e.g., Barancourt et al., 1992; Bacchi and Kottegoda, 1995; Mascaro, 2013). However, the rainfall amount, which is in the form of regionalized variables, is spatially correlated over a certain distance (Panthou et al., 2014; de Luca, 2014). A regionalized variable is any variable distributed in space. Random field theory is recognized as a suitable theory for describing regionalized variables (Vanmarcke, 1977) and has been proven effective for the regionalized variables (e.g., Dasaka and Zhang, 2012; Li et al., 2015). The random field theory has also been used in spatial storm analysis (e.g., Rodríguez-Iturbe et al., 1986; Bouvier, 2003) and adopted to describe storm spatial structures (e.g., Zawadzki, 1973; Lebel et al., 1987; Gyasi-Agyei and Pegram, 2014).

Research on spatial rainfall distribution using statistical models has been performed in Hong Kong for different engineering purposes (Leung and Law, 2002; Jiang and Tung, 2014; AECOM and Lin, 2015). Leung and Law (2002) conducted kriging analysis on Hong Kong hourly rainfall data in 1997 and 1998. Rainfall contours were interpolated to qualitatively estimate possible flooding locations. Jiang and Tung (2014) derived rainfall depth-duration-frequency relations at ungauged sites in Hong Kong using an ordinary kriging approach based on annual maximum daily rainfall data. The extreme rainfall estimates are sensitive to assumed statistical parameters and uncertainties of the interpolation method.

The storm characteristics such as distribution form and spatial correlation are not sufficiently analyzed when studying the hydrological response of a target system such as a slope safety system. In particular, limited attention has been paid to event-based spatial characteristics of large rainstorms in Hong Kong, whose patterns and structures are as useful as the statistical trend based on historic rainfall records, especially when one needs to select large rainstorms for landslide risk assessment. Sufficient information should be provided, including both spatial variation and correlation. However, several key questions have not been answered. Can the spatial precipitation distribution of a large storm be represented using a particular spatial form? How does the spatial correlation of rainfall change with the rainstorm magnitude? What are the key factors that influence the spatial structure of rainfall distribution? Such questions motivate the present study on the spatial characteristics of large rainstorms over hilly terrains in Hong Kong.

The objective of this paper is to identify the spatial variations and correlation of large rainstorms in Hong Kong. Three large storms that caused the most severe landslide hazards in Hong Kong in the past 20 years are selected for study. These storms were often referred to in Hong Kong as reference storms in preparing engineering measures for landslide hazard mitigation. The results are therefore expected to provide valuable information for landslide hazard analysis and risk management. 


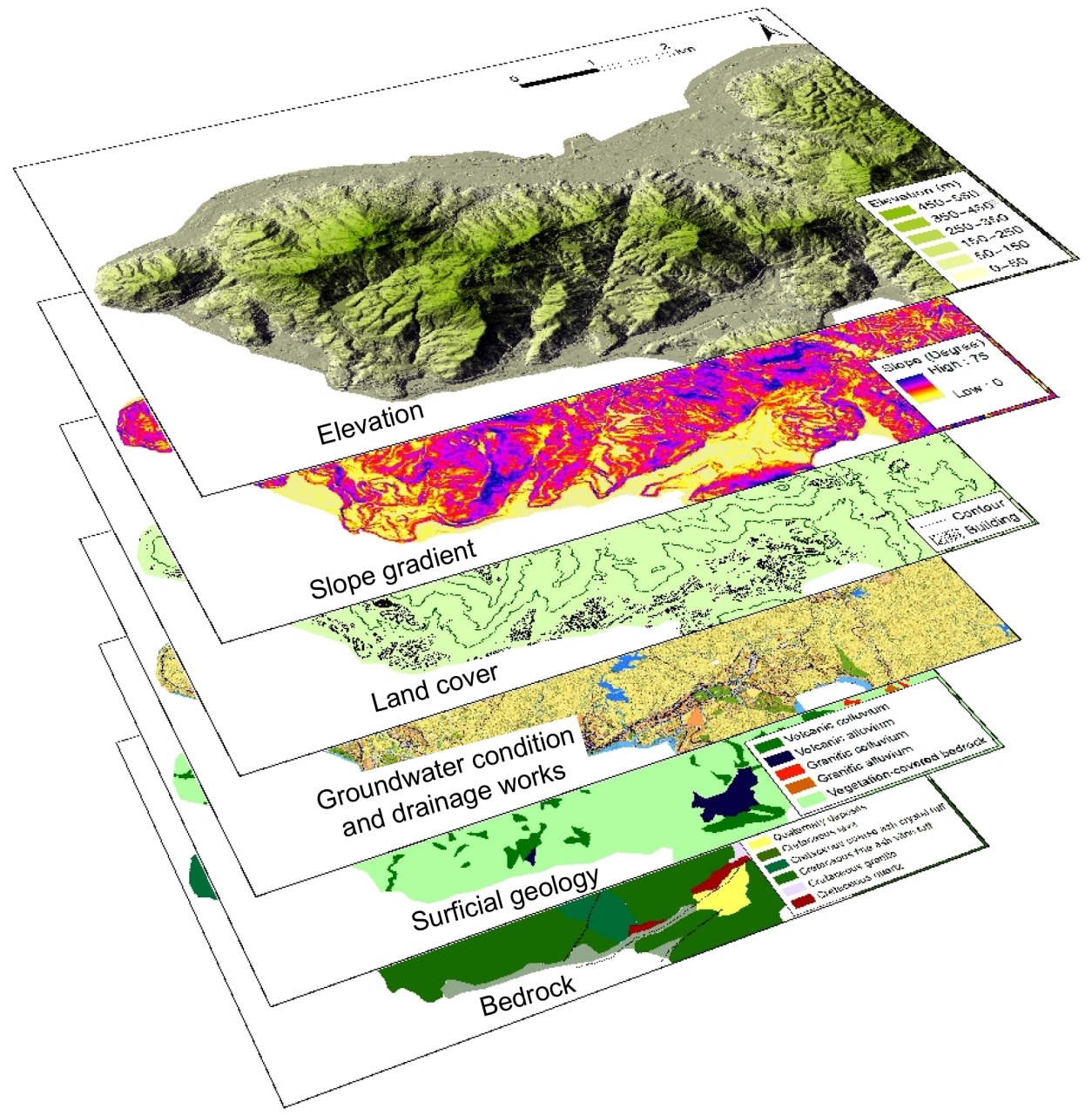

Figure 2. Geotechnical and environmental factors that affect the triggering of natural terrain landslides.

\section{Topography and general rainfall distribution in Hong Kong}

Hong Kong is located at the southeast coast of China. The subtropical climate in Hong Kong is characterized by notable dry and wet seasons. About $85 \%$ of the annual rainfall is recorded during the wet season from April to September. Storms with high intensity and short duration in Hong Kong are typically associated with southwest monsoon or tropical cyclones. The ground surface elevation on the GIS platform is shown in Fig. 3. The two highest mountain peaks in Hong Kong are Tai Mo Shan (near rain gauge N14) and Lantau Peak (near rain gauge N21), with peak elevations of 957 and $934 \mathrm{~m}$ a.s.l., respectively. Both the moisture movements and the topography determine the distribution characteristics (e.g., agglomerate and local gradient) of rainfall in the spatial domain.

AECOM and Lin (2015) studied the orographic factors of rainfall spatial distribution based on historical records. A spatial distribution of orographic intensification factors has been developed based on historical hourly data. The $24 \mathrm{~h}$ orographic intensification factors at a resolution of $5 \mathrm{~km} \times 5 \mathrm{~km}$ are shown in Fig. 4. The factors for the land area are in general larger than those for the sea area. The higher the elevation is, the larger the orographic intensification factor. Two of the highest intensity regions are located at Tai Mo Shan in New Territories and Lantau Peak on Lantau Island. The trend of the factors coincides with the mountain range alignment, i.e., around $\mathrm{N} 45^{\circ} \mathrm{E}$.

The magnitude of storms can be assessed corresponding to a depth-area relation, and characterized by the probable maximum precipitation (PMP). PMP is frequently used to quantify extreme storm events (WMO, 2009). The scenarios of 4 and 24h PMP for Hong Kong have been assessed by the Hong Kong Observatory and AECOM (Chang and Hui, 2001; AECOM and Lin, 2015). AECOM and Lin (2015) updated the $24 \mathrm{~h}$ PMP for Hong Kong considering the local orographic intensification. The trend surface is an expectedvalue surface. The trend surfaces of $24 \mathrm{~h}$ PMP with different storm centers have been updated by AECOM and Lin (2015), 


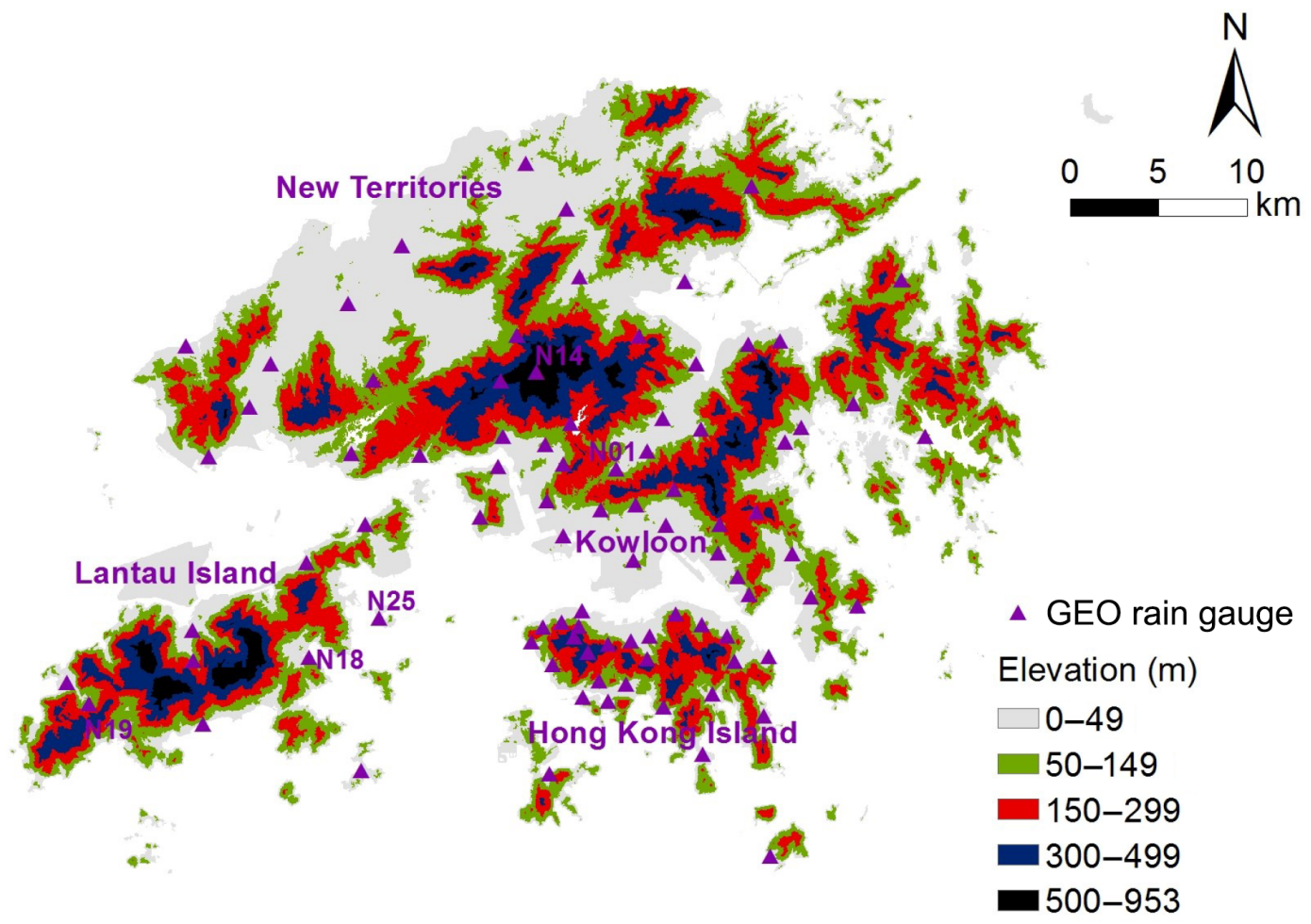

Figure 3. The GEO rain-gauge network in Hong Kong.

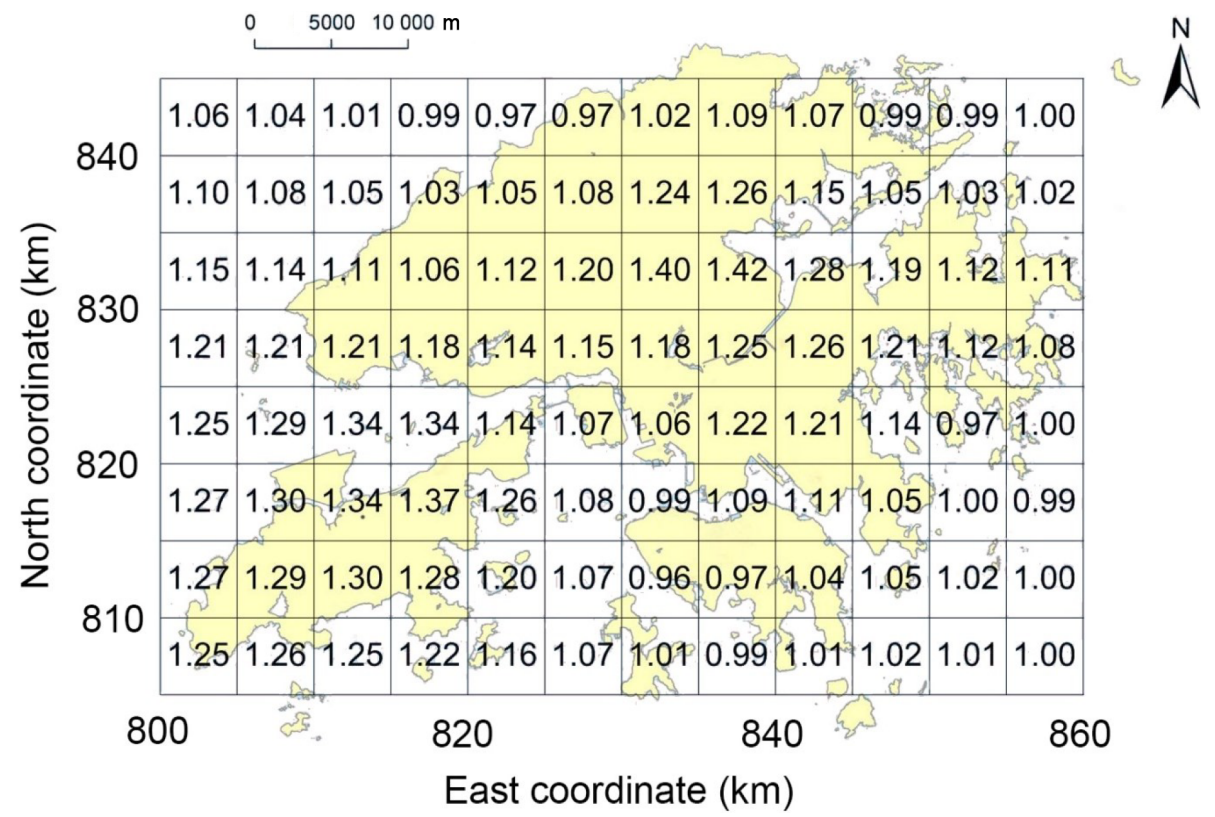

Figure 4. The $24 \mathrm{~h}$ orographic intensification factors in Hong Kong (modified from AECOM and Lin, 2015).

and the typical trends are shown in Fig. 5. The trend surfaces are derived based on the historical hourly rainfall. According to the $24 \mathrm{~h}$ PMP updating study, an elliptical isohyet is recommended as a generalized convergence pattern. For storms cantered at Tai Mo Shan, the orientation of $22.5^{\circ}\left(\mathrm{N} 67.5^{\circ} \mathrm{E}\right)$ is found to be the most critical. 
(a)

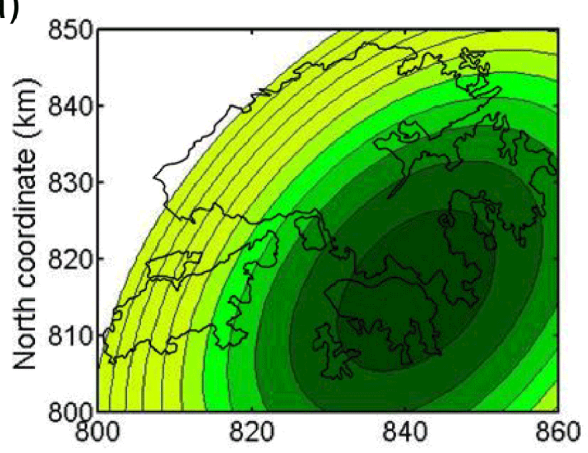

(c)

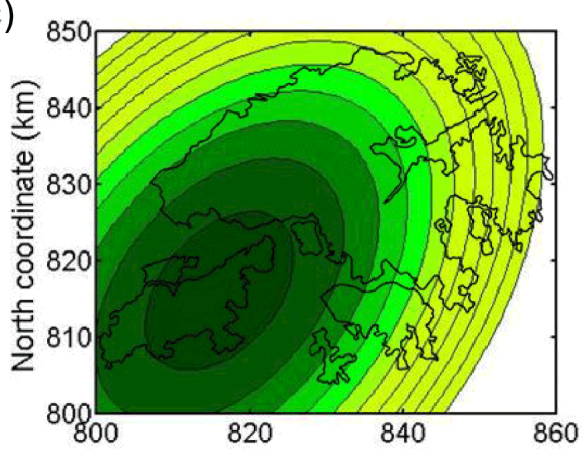

(e)

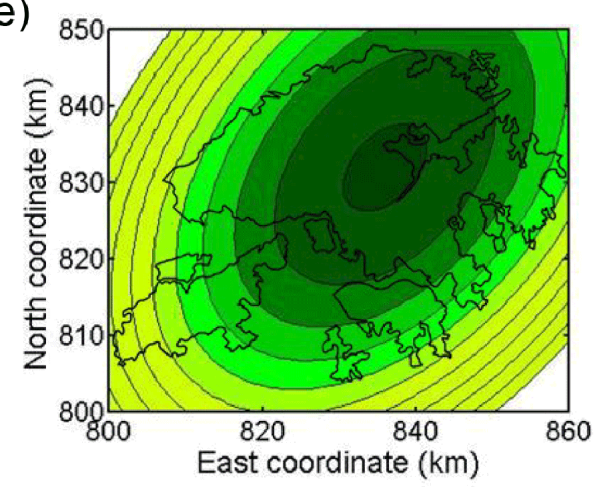

(b)

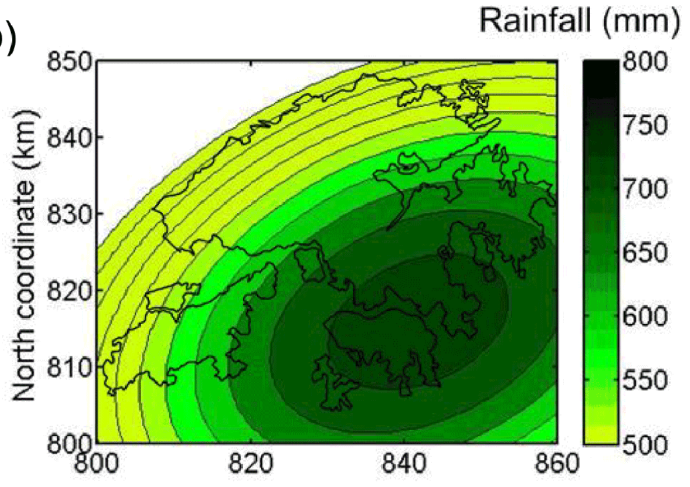

(d)

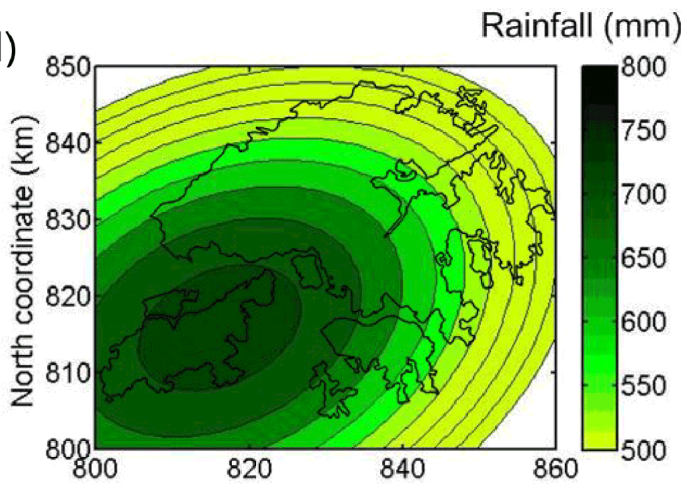

(f)

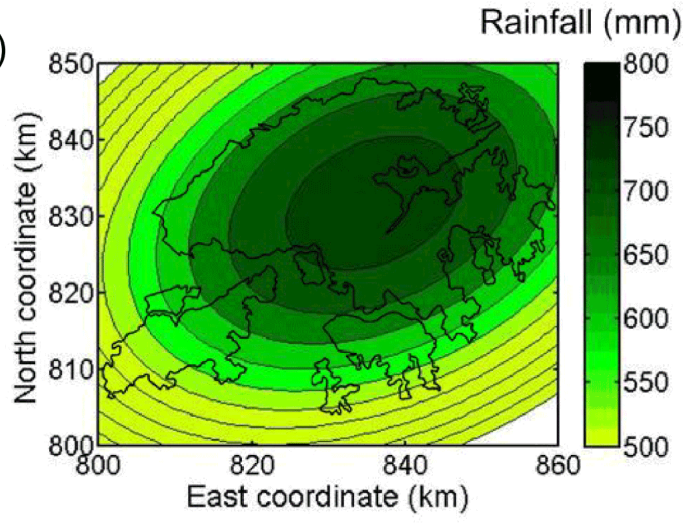

Figure 5. Trend surfaces of $24 \mathrm{~h}$ PMP with (a) NE-SW orientation $45^{\circ}$; (b) ENE-WSW orientation $22.5^{\circ}$ centered at Hong Kong Island; (c) NE-SW orientation $45^{\circ}$; (d) ENE-WSW orientation $22.5^{\circ}$ centred at Lantau Island; (e) NE-SW orientation $45^{\circ}$; and (f) ENE-WSW orientation $22.5^{\circ}$ centred at Tai Mo Shan (modified from AECOM and Lin, 2015).

\section{Progression and precipitation data of three large storms}

The most traditional way to describe the rainstorm severity is by return period, which is recognized as a combination of intensity and duration. Another measure of the severity of a storm is the consequence of the storm, such as rain-induced landslides or flooding. An index measuring the potential to trigger landslides, named "Landslide Potential Index (LPI)", is used in Hong Kong (CEDD, 2009). The LPI is based on the historic records of landslide events since 1984. For instance, a storm in late July 1994 caused five fatalities and its LPI was 10 . The value of LPI can be greater than 10 if a storm is more damaging than the July 1994 storm. According to the LPI, the top three largest storms in the past 20 years were the 5-7 June 2008 storm, the 17-21 August 2005 storm, and the 23 July 1994 storm. Each of these three storms had an LPI around 10 and led to fatalities. Thus, the three storm events are selected as indicative large storms to conduct spatial correlation analysis in this paper.

The rainfall data in this study are provided by Geotechnical Engineering Office (GEO) and the Hong Kong Obser- 
(a)

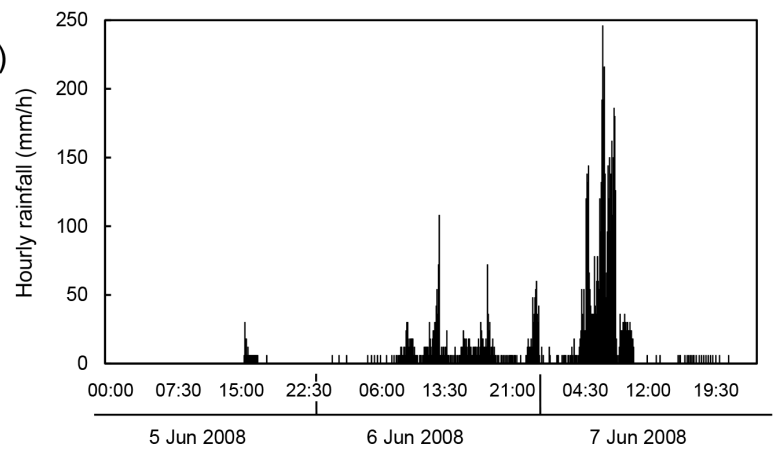

(b)

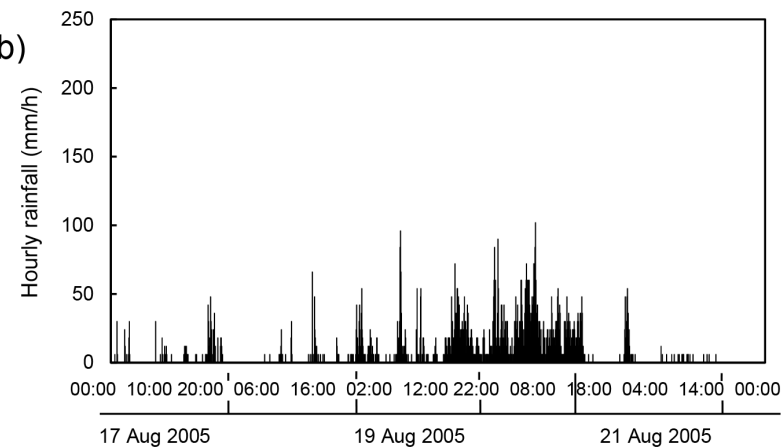

(c)

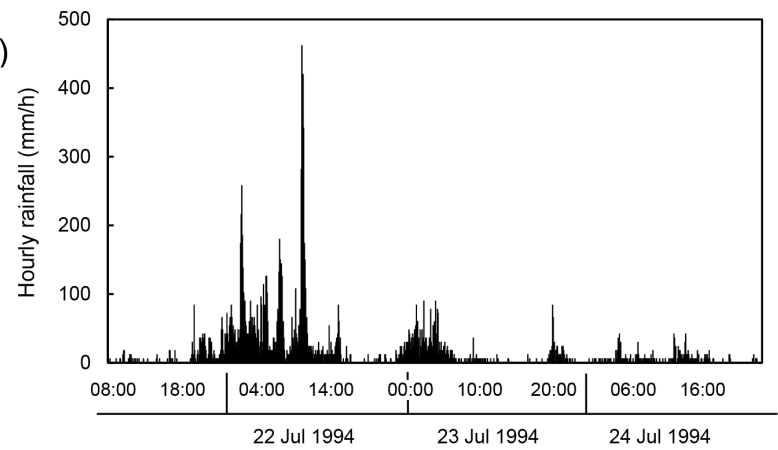

Figure 6. Hyetographs of three storms: (a) 5-7 June 2008 storm, Station N19; (b) 17-21 August 2005 storm, Station N01; (c) 2224 July 1994 storm, Station N14.

vatory in Hong Kong. The GEO and Hong Kong Observatory rain gauge networks comprise 88 and 46 stations, respectively (Fig. 3). The rain gauges are more concentrated in the northern Hong Kong Island and Kowloon, where the population density is high. The raw digital data at $5 \mathrm{~min}$ interval from the high-quality network ensure the reliability of this study. The data cover the period from 00:00 LT on 5 June to 24:00 LT on 7 June 2008, from 00:00 LT on $17 \mathrm{Au}-$ gust to 24:00 LT on 21 August 2005, and from 00:00 LT on 22 July to 24:00 LT on 24 July 1994. Some of the rain gauges had not been installed in July 1994. The numbers of effective rain gauges for the three events are 105, 112, and 56, respectively. The three storm hyetographs corresponding to the maximum local precipitation depth are shown in Fig. 6 . The 17-21 August 2005 storm is more moderate in short du- (a)

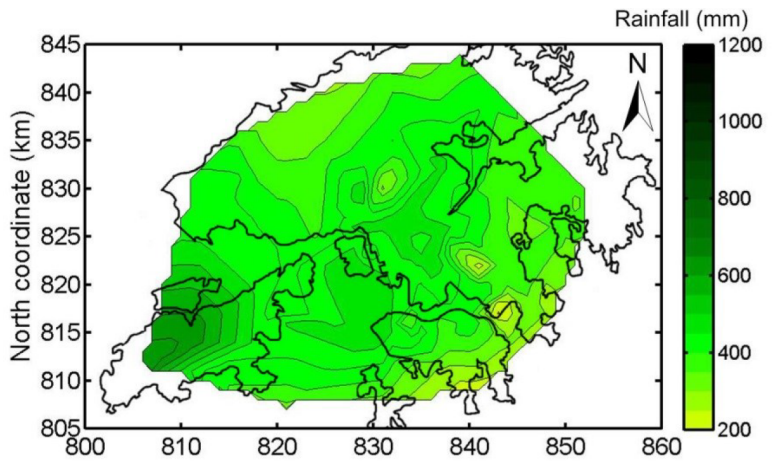

(b)

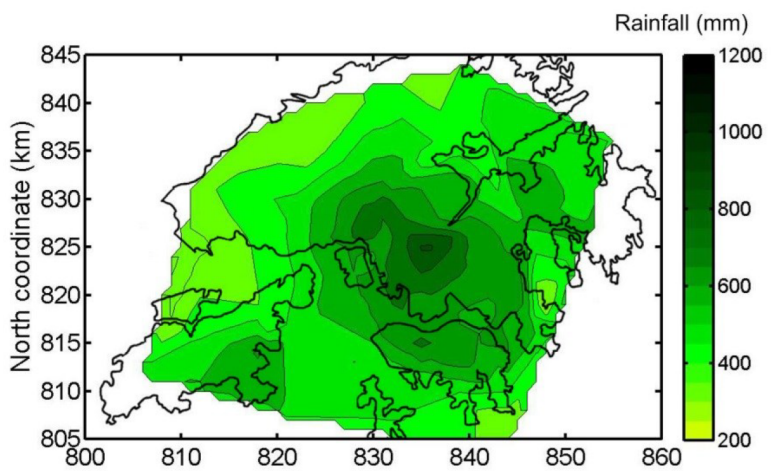

(c)

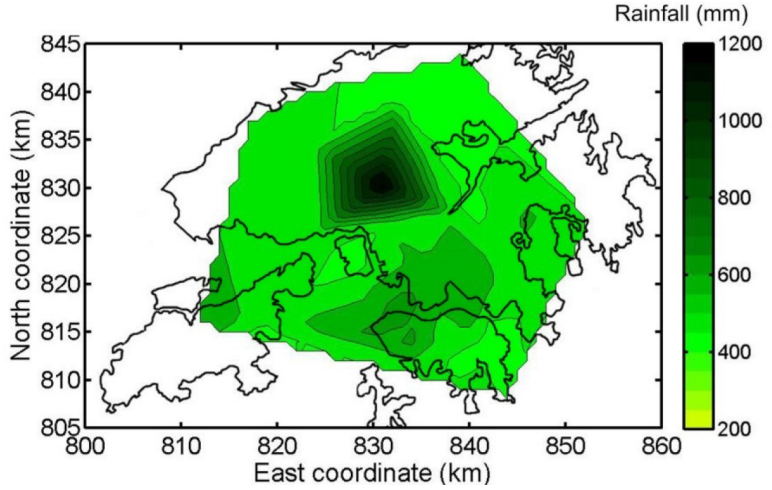

Figure 7. Spatial distribution of the total rainfall amount: (a) the 5-7 June 2008 storm; (b) the 17-21 August 2005 storm; (c) the 22-24 July 1994 storm.

rations compared with the 5-7 August 2008 storm and the 22-24 July 1994 storm.

\subsection{The 5-7 June 2008 storm}

According to Hong Kong Observatory, the weather was influenced by an active low pressure trough over the south China coastal area during the first 10 days of June 2008, and was heavily rainy and thundery. Figure 7 a shows contours of the total rainfall amount of the 5-7 June 2008 storm. The maximum total rainfall amount was $670 \mathrm{~mm}$. The storm center was on the southeast of Lantau Island. The magnitudes of 
(a)

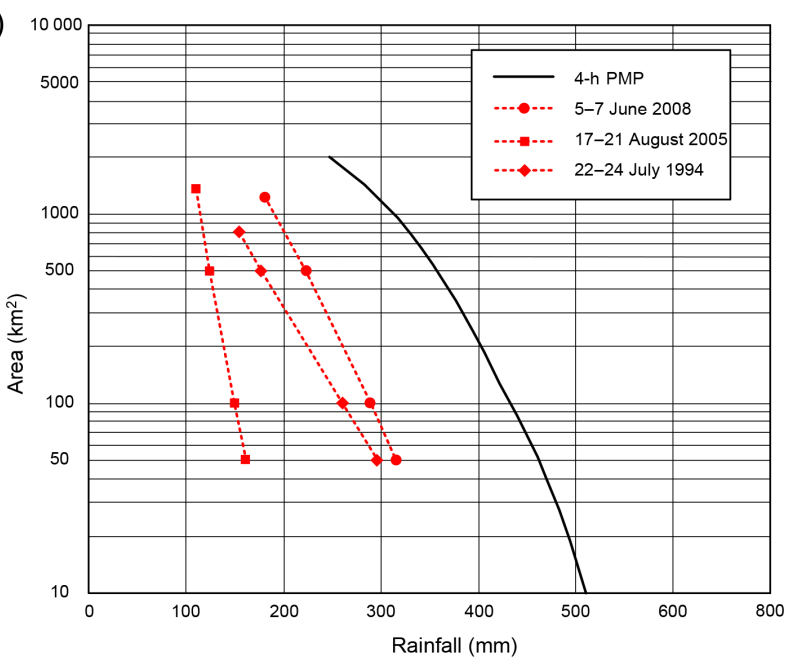

(b)

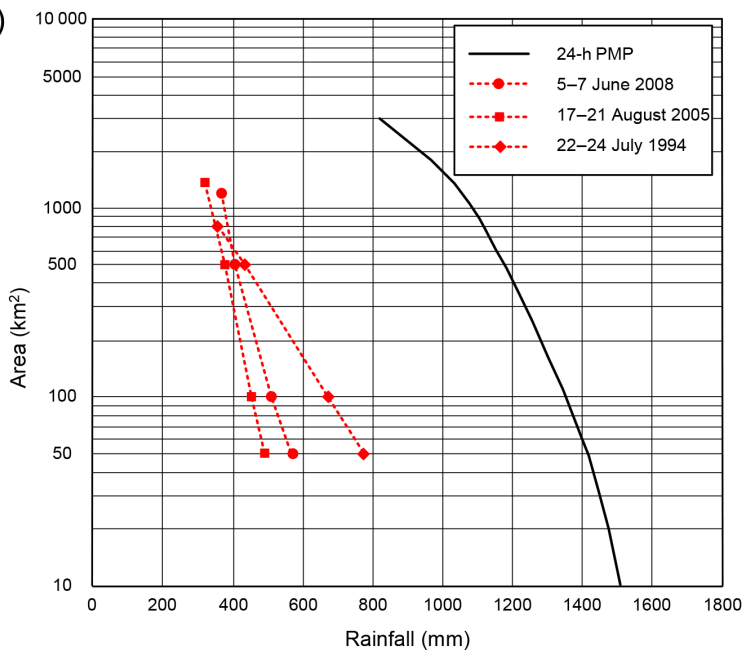

Figure 8. Magnitudes of the three storms characterized by (a) $4 \mathrm{~h}$ PMP and (b) $24 \mathrm{~h}$ PMP (modified from AECOM and Lin, 2015).

the storm characterized by 4 and $24 \mathrm{~h}$ PMP (AECOM and Lin, 2015) are shown in Fig. 8. From the depth-area relationships, when the area is in the range of $50-1100 \mathrm{~km}^{2}$, the maximum rolling $4 \mathrm{~h}$ rainfall of the 5-7 June 2008 storm has a return period of 1100 years, corresponding to $60-67 \%$ of the $4 \mathrm{~h}$ PMP, while the return period for the $24 \mathrm{~h}$ rainfall is 200 years, corresponding to $33-41 \%$ of the $24 \mathrm{~h}$ PMP. The $4 \mathrm{~h}$ maximum rolling rainfall value is calculated as the maximum values of rainfall in 4 consecutive hours on a hyetograph. The storm caused 2400 natural terrain landslides ( $\mathrm{Li}$ et al., 2009), including many debris flows that affected developed regions, leading to two fatalities (CEDD, 2008). The LPI value was recognized as 12 .

The maximum rolling rainfall values at different locations may not be in the same period, though most of them tend to be in the same period. Hazard consequences are more related to the maximum rolling rainfall values than instantaneous consequences are (Dai and Lee, 2001). In formulations for a hydrological model, the effect of the timescale of aggregation of the rainfall data and the hydrological response of catchments of different sizes should be investigated in order to identify the critical scale on which the resulting discharge will be the largest and could potentially generate flash floods.

The most concentrating periods of precipitation are selected. Figure 9 shows the instantaneous rainfall process from 06:55 to 07:35 LT on 7 June 2008. During this period, the vapour was concentrated on the southwest of Lantau Island and transported northeast across the mountains on Lantau Island. A large amount of precipitation was retained on the island.

\subsection{The 17-22 August 2005 storm}

August 2005 was much wetter than normal. A very active southwest monsoon during 17-22 August brought in plenty of moisture. Figure $7 \mathrm{~b}$ shows contours of the total amount of rainfall. The maximum total rainfall amount was $890 \mathrm{~mm}$. The storm center was at the middle of the territory, Sha Tin. From Fig. 8, both the maximum rolling $4 \mathrm{~h}$ rainfall and $24 \mathrm{~h}$ rainfall of the 17-22 August 2005 storm are least critical among the three storms investigated in this paper. The storm caused 229 reported landslides, resulting in one fatality. The LPI value is 10 (Kong and $\mathrm{Ng}, 2006$ ).

Figure 10 shows the instantaneous rainfall process from 10:35 to 11:15 LT on 20 August 2005, which is recognized as the heaviest rainfall period in this storm event. The prevailing moisture inflow mainly came southerly during this period. The rainfall center concentrated on the south of Tai Mo Shan.

\subsection{The 21-24 July 1994 storm}

The total precipitation amount in the storm event from 21 to 24 July 1994 was recorded as the highest for any consecutive days in July. The weather was related to a trough of low pressure (Tam et al., 1995). Figure 7c shows contours of the total amount of rainfall of this storm concentrating in the middle of the New Territories, at Tai Mo Shan. The maximum total rainfall amount was $1450 \mathrm{~mm}$. In Fig. 8, the maximum rolling $24 \mathrm{~h}$ rainfall is the most critical, especially for a smaller area. The storm caused 820 natural terrain landslides and 451 man-made slope failures, resulting in five fatalities and four injuries. The LPI value is 10 (Chan, 1995).

Figure 11 shows the instantaneous rainfall process from 15:00 to 15:40 LT on 23 July 1994, which records the heaviest rainfall process in this storm event. During this period, the moisture air came from on the northwest of Tai Mo Shan. Most of precipitation concentrated on Tai Mo Shan, and the spatial distribution of rainfall was quite uneven. As the moisture flux rose across Tai Mo Shan, a large amount of moisture began to fall as rain. The orographic intensification effect was very significant in this rainstorm event. 
(a)

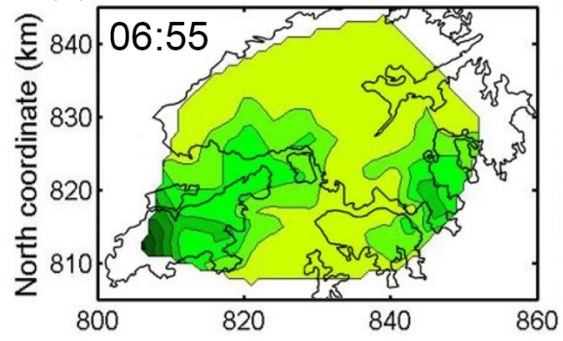

(d)

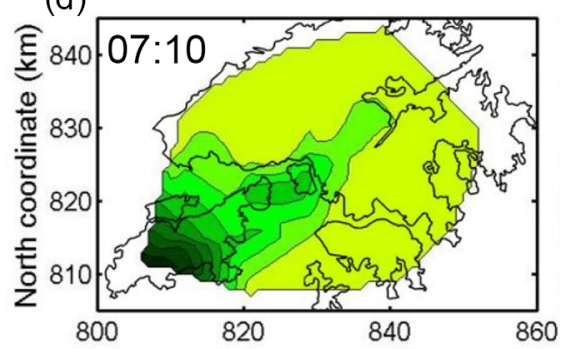

(g)

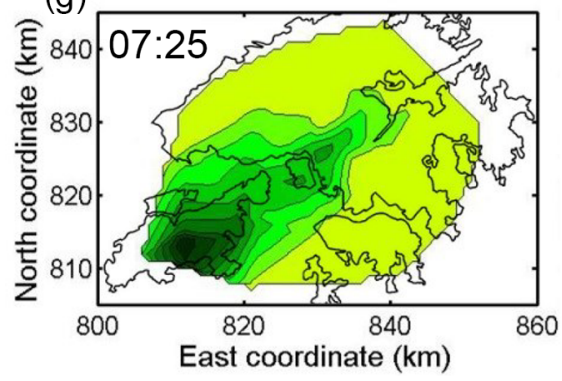

(b)

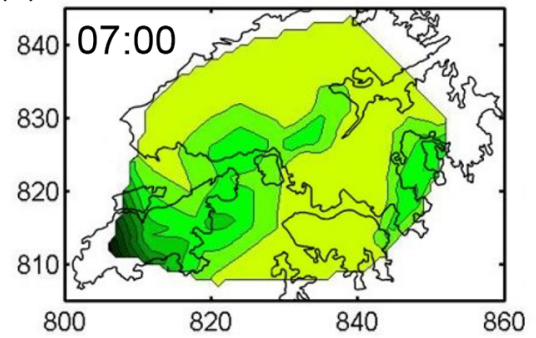

(e)

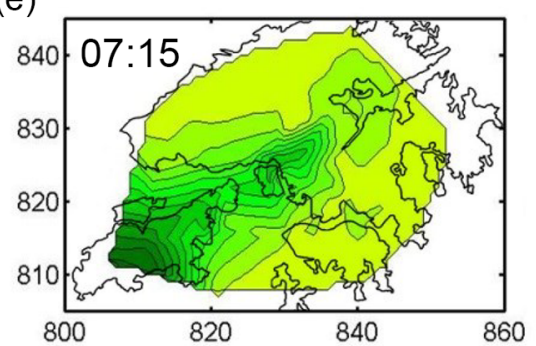

(h)

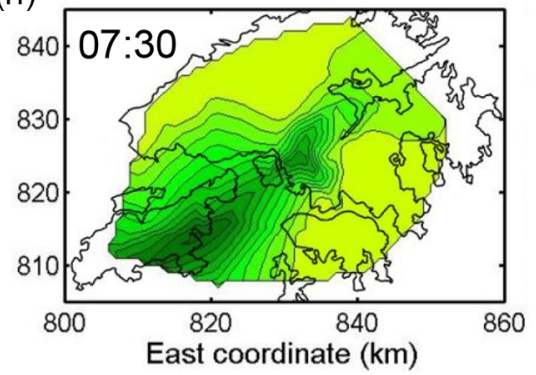

(c)

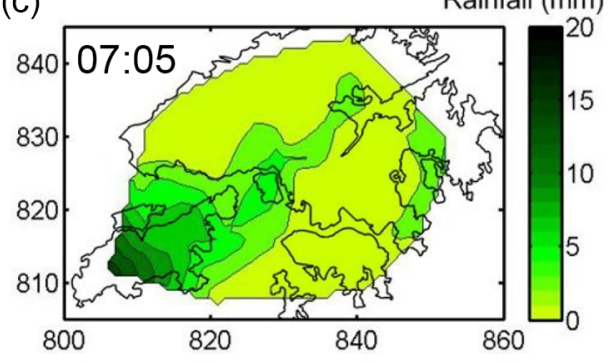

(f)

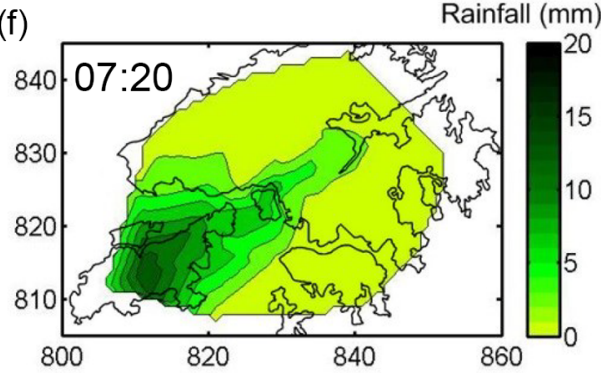

(i) Rainfall $(\mathrm{mm})$

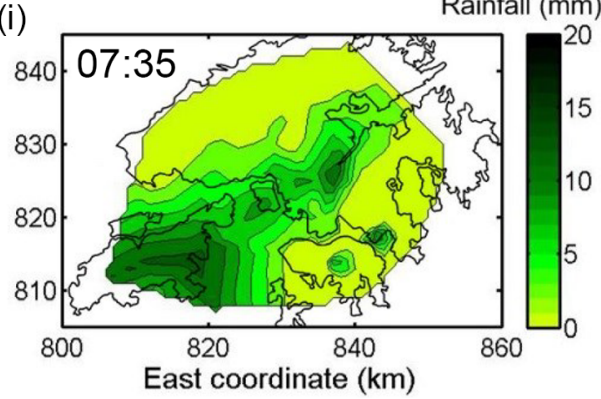

Figure 9. Instantaneous rainfall process from 06:55 to 07:35 LT on 7 June 2008.

\subsection{Summary of the three large storms}

All the aforementioned three storms are related to monsoons other than typhoons. The meteorological factors for these storms are beyond the scope of this paper. This research focuses on the areal distribution of precipitation, which is believed to be more relevant to the evaluation of the performance of the slope safety system. Thus the maximum rolling rainfall values are estimated in different durations. According to the records from the automatic rain gauges, the maximum rolling rainfall among all the rain-gauge stations in each of the three events can be calculated. The corresponding peak values and stations are summarized in Table 1. The 22-24 July 1994 storm is the largest among the three storms with regard to the amounts of the maximum rolling $1 \mathrm{~h}$ and $24 \mathrm{~h}$ rainfall. However, in terms of the maximum rolling $4 \mathrm{~h}$ rainfall, the 5-7 June 2008 storm is the most critical.

The contours of the total rainfall for the three storms, interpolated using a triangular method, are shown in Fig. 7. The total precipitation amount of the 5-7 June 2008 storm is the smallest among the three events, while that of the 2124 July 1994 storm is the largest due to its longer duration.
However, the LPI value for the 5-7 June 2008 storm is 12 , larger than those of the other two storms; that is, the 57 June 2008 storm is the largest one in terms of damage. One of the reasons is that the variability of spatial and temporal distributions of the storm affects both the infiltration dynamics of the surface soil and the water levels above and below the ground surface. The entire hydrological system is governed by the spatial and temporal distribution of rainfall.

\section{Methodology of spatial analysis}

The varying space-time distribution of rainfall in Hong Kong is a result of the interaction between governing meteorological covariates and local hilly terrain. Instead of attempting to use a physical model to capture the spatial characteristics, our analysis presents a two-step approach in which a surface trend is firstly established to assess the spatial distribution of the rainfall amount in a fixed duration, followed by a further analysis of the spatial correlation of the detrended residuals. 
(a)

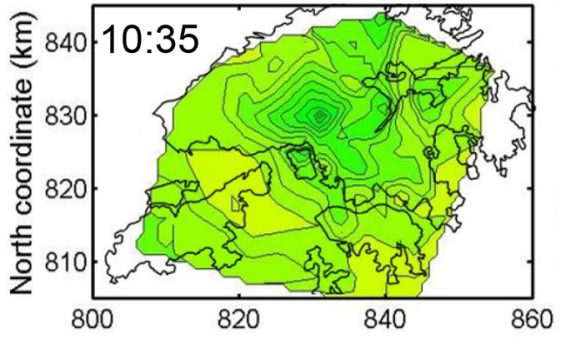

(d)

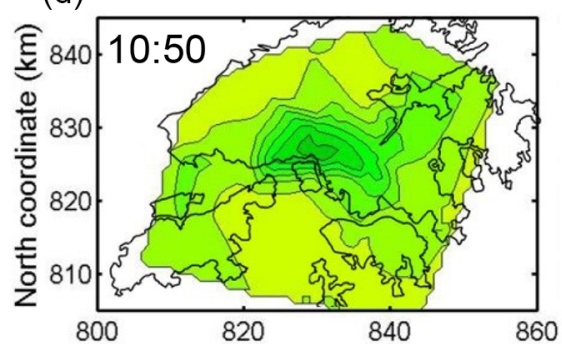

(g)

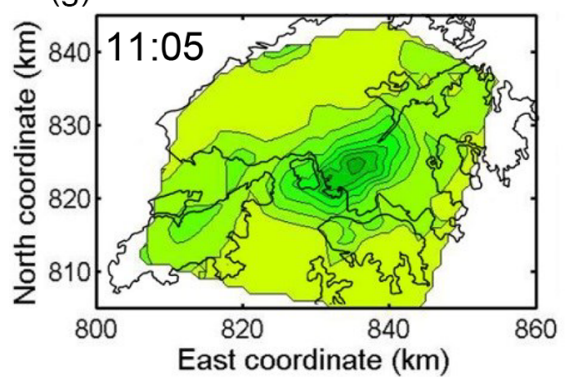

(b)

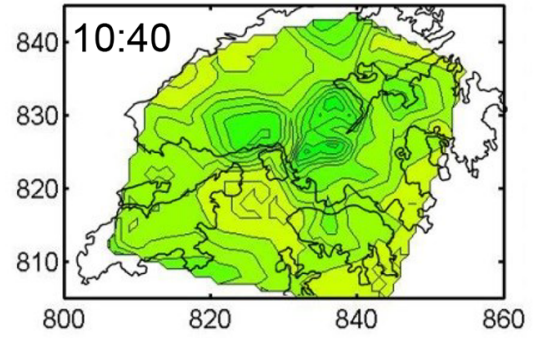

(e)

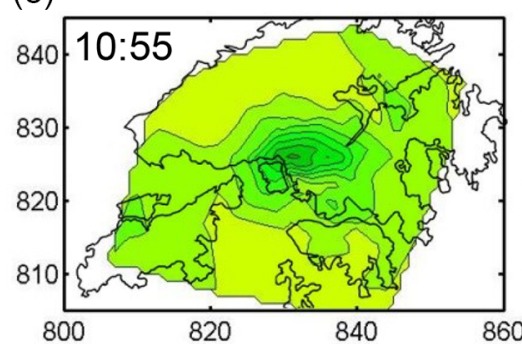

(h)

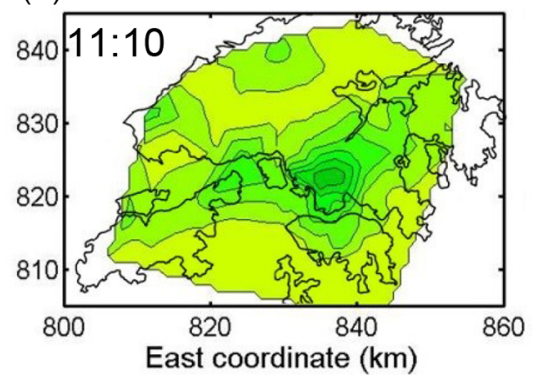

(c)

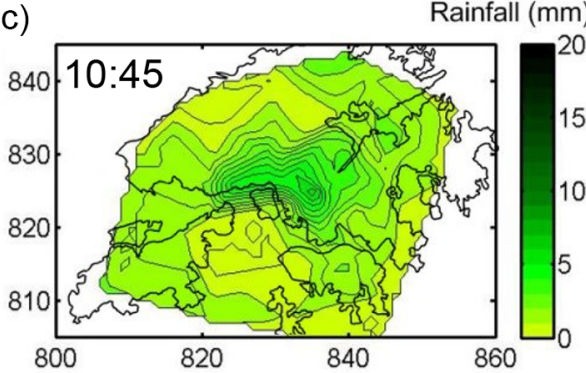

(f)

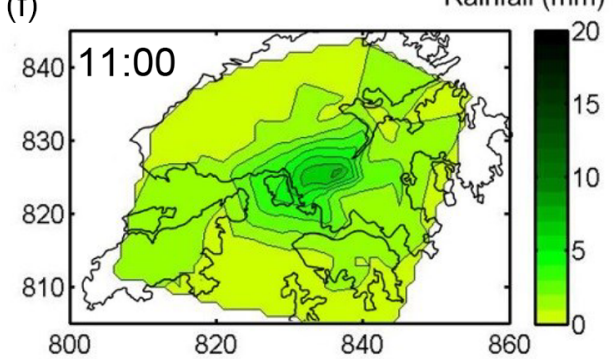

(i)

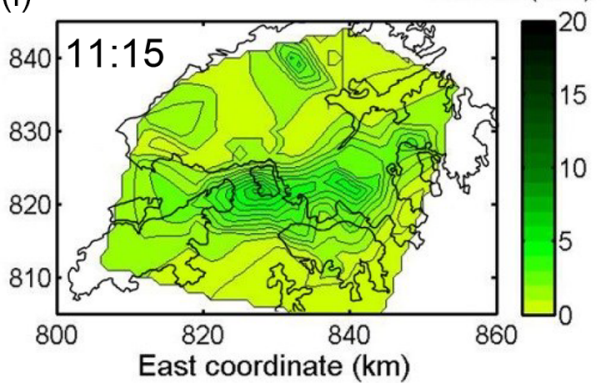

Figure 10. Instantaneous rainfall process from 10:35 to 11:15 LT on 20 August 2005.

\subsection{Determination of the expected precipitation trend surface}

A storm is a phenomenon with gradual geographical changes in space; the rainfall amount can be simulated as a spatially correlated random field superimposed on a trend surface (Grimes and Pardo-Igúzquiza, 2010). Such an artificial rainfall trend surface can be used to represent design storms. One could comprehend that the rainfall is correlated with the local terrain and the design storm centers are likely to be around the mountain peaks. Hong Kong has a relatively small area, and an individual storm is usually designed to have one or two centers for engineering design purposes (AECOM and Lin, 2015). Distinguishing two peaks is not necessary, as the distance between any two peaks will be small with regard to the scale of a typical rainstorm.

Based on random field theory (Vanmarcke, 1977), the trend surface is the expected value of the precipitation distributed over the rainfall domain, while the residuals are stationary and not affected by any shift in the coordinate system. Thus, the first step is to divide the spatial distribution into a trend surface and residuals by finding a trend surface fitting function. Though most natural processes such as storms exhibit spatial variability with complex trends, this paper uses a polynomial function for simplicity, with observations of a storm denoted as $z_{i}\left(x_{i}, y_{i}\right)(i=1,2, \ldots, n)$. The fitted values are $\hat{z}_{i}=\left(x_{i}, y_{i}\right)$ :

$z_{i}\left(x_{i}, y_{i}\right)=\hat{z}_{i}\left(x_{i}, y_{i}\right)+\varepsilon_{i}$,

where $x$ and $y$ define the location, and $\varepsilon_{i}$ are residuals. The second-order polynomial trend surface is as follows:

$\hat{z}_{i}=a_{0}+a_{1} x_{i}+a_{2} y_{i}+a_{3} x_{i}^{2}+a_{4} x_{i} y_{i}+a_{5} y_{i}^{2}$.

The coefficients, $a_{0}, a_{1}, \ldots, a_{5}$, are determined by minimizing the sum of the squares of the error term using the ordinary least-squares (OLS) analysis (Journel and Huijbergts, 1978):

$Q=\min \sum_{i=1}^{n} \varepsilon_{i}^{2}=\min \sum_{i=1}^{n}\left[z_{i}\left(x_{i}, y_{i}\right)-\hat{z}_{i}\left(x_{i}, y_{i}\right)\right]^{2}$.

The computed trend surfaces for the total rainfall amounts of the three storms and the detrended residuals are shown in Fig. 12. The residuals of the rainfall amounts in different 

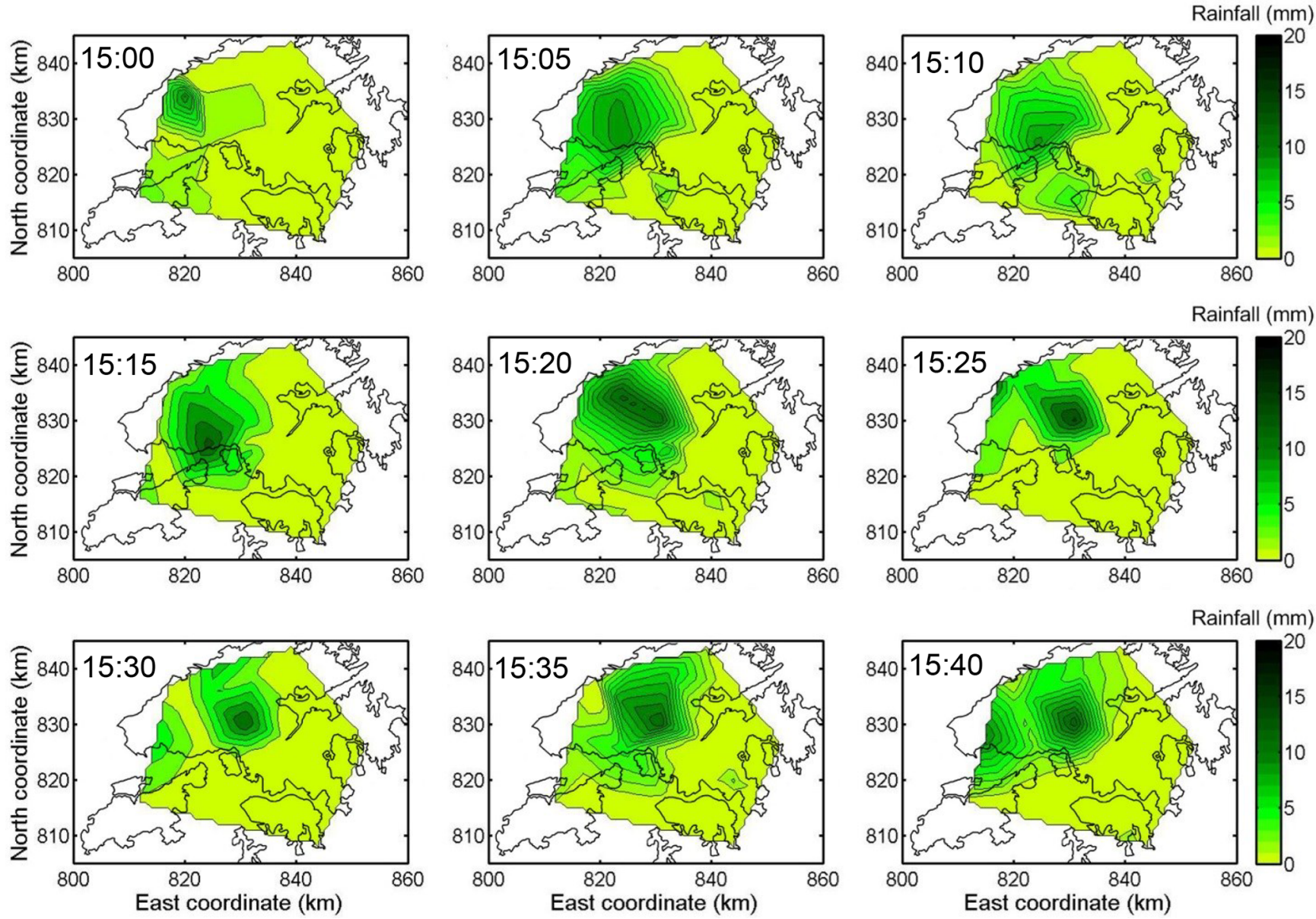

Figure 11. Instantaneous rainfall process from 15:00 to 15:40 LT on 23 July 1994.

Table 1. Values of maximum rolling rainfall of three landslide-triggering storms in Hong Kong.

\begin{tabular}{|c|c|c|c|c|c|c|}
\hline \multirow[t]{2}{*}{ Duration } & \multicolumn{2}{|c|}{ 5-7 Jun 2008 storm } & \multicolumn{2}{|c|}{ 17-21 Aug 2005 storm } & \multicolumn{2}{|c|}{ 22-24 Jul 1994 storm } \\
\hline & $\begin{array}{r}\text { Amount } \\
(\mathrm{mm})\end{array}$ & Station & $\begin{array}{r}\text { Amount } \\
(\mathrm{mm})\end{array}$ & Station & $\begin{array}{r}\text { Amount } \\
(\mathrm{mm})\end{array}$ & Station \\
\hline $1 \mathrm{~h}$ & 154 & $\mathrm{~N} 21$ & 82 & $\mathrm{~N} 25$ & 212 & N14 \\
\hline $4 \mathrm{~h}$ & 384 & N19 & 174 & N18 & 365 & $\mathrm{~N} 14$ \\
\hline $24 \mathrm{~h}$ & 623 & N19 & 570 & N01 & 956 & $\mathrm{~N} 14$ \\
\hline 2 day & 672 & N19 & 768 & N01 & 1216 & N14 \\
\hline 4 day & 768 & N19 & 890 & N01 & 1450 & N14 \\
\hline
\end{tabular}

Table 2. Locations of maximum rainfall on the trend surfaces $(\mathrm{km})$

\begin{tabular}{llll}
\hline Duration & $\begin{array}{l}\text { 5-7 Jun 2008 } \\
\text { storm (E, N) }\end{array}$ & $\begin{array}{l}\text { 17-21 Aug 2005 } \\
\text { storm (E, N) }\end{array}$ & $\begin{array}{l}\text { 22-24 Jul 1994 } \\
\text { storm (E, N) }\end{array}$ \\
\hline $4 \mathrm{~h}$ & $(774,778)$ & $(822,816)$ & $(822,836)$ \\
$12 \mathrm{~h}$ & $(764,788)$ & $(825,822)$ & $(822,835)$ \\
$24 \mathrm{~h}$ & $(781,752)$ & $(829,819)$ & $(823,833)$ \\
$36 \mathrm{~h}$ & $(769,747)$ & $(830,820)$ & $(825,826)$ \\
\hline
\end{tabular}

durations are often assumed to be stationary. Taking the maximum $4 \mathrm{~h}$ rolling rainfall as an example, the trend surface is

$$
\begin{aligned}
\hat{z}= & -45984-0.0337 x+0.1527 y \\
& +\left(-1.5297 x^{2}+3.4783 x y-2.7125 y^{2}\right) \times 10^{-7} .
\end{aligned}
$$

The peak point on the surface is $(77429,77793)$; the maximum $4 \mathrm{~h}$ rainfall on the trend surface is $425 \mathrm{~mm}$. The maximum points (extreme values) on the trend surfaces of the three storms are summarized in Table 2 . The major and mi- 

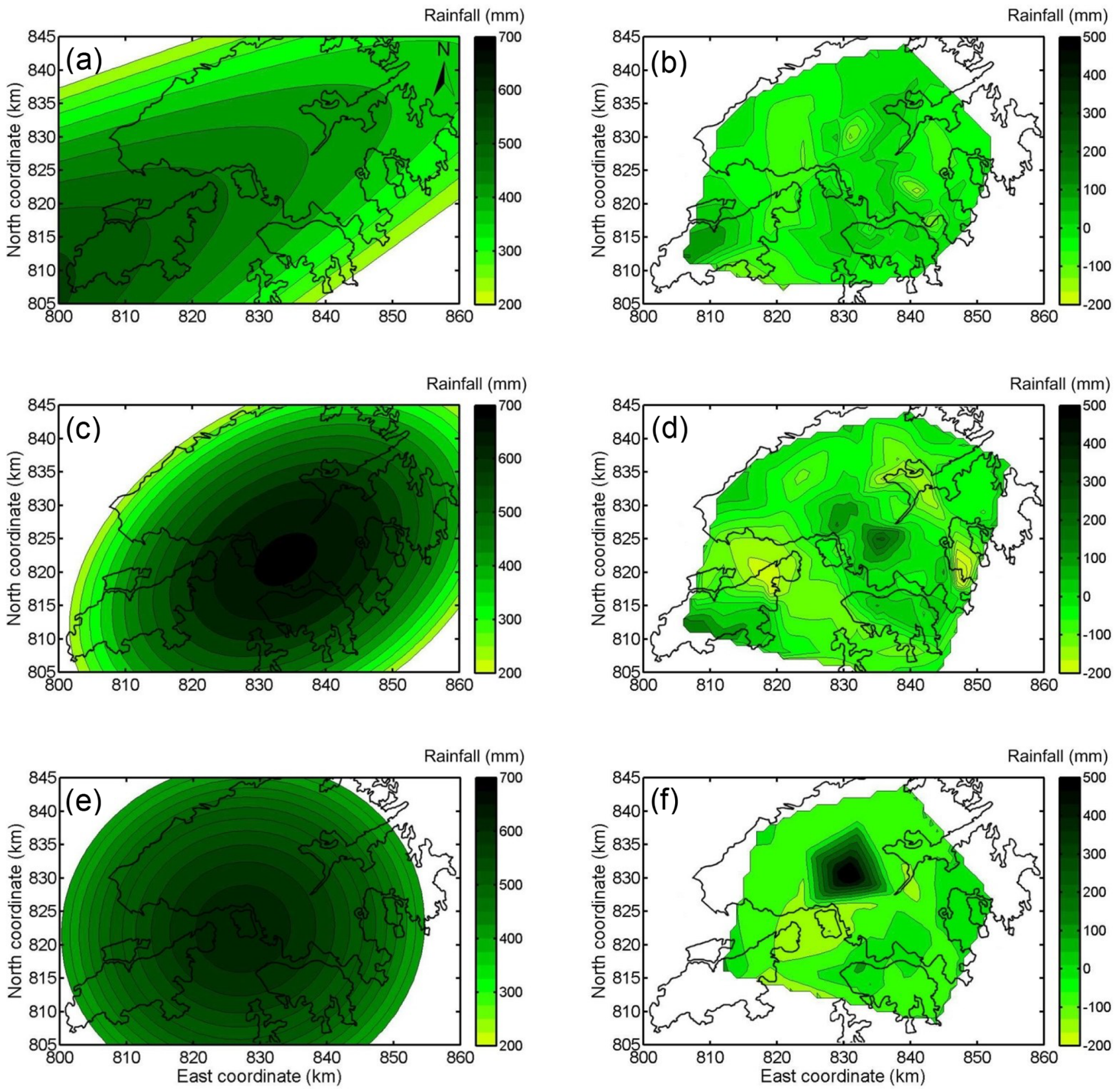

Figure 12. Trend surfaces and residuals of the total rainfall amounts: (a) and (b) show the 5-7 June 2008 storm; (c) and (d) show the 17-21 August 2005 storm; (e) and (f) show the 22-24 July 1994 storm.

Table 3. Directions and lengths of the axes of trend surfaces.

\begin{tabular}{|c|c|c|c|c|c|c|c|c|c|}
\hline \multirow[t]{2}{*}{ Duration } & \multicolumn{3}{|c|}{ 5-7 Jun 2008 storm } & \multicolumn{3}{|c|}{ 17-21 Aug 2005 storm } & \multicolumn{3}{|c|}{ 22-24 Jul 1994 storm } \\
\hline & $\begin{array}{r}\text { Major axis } \\
\text { direction }\left(^{\circ}\right)\end{array}$ & $\begin{array}{r}\text { Major axis } \\
\text { length }(\mathrm{km})\end{array}$ & $\begin{array}{r}\text { Minor axis } \\
\text { length }(\mathrm{km})\end{array}$ & $\begin{array}{r}\text { Major axis } \\
\text { direction }\left(^{\circ}\right)\end{array}$ & $\begin{array}{r}\text { Major axis } \\
\text { length }(\mathrm{km})\end{array}$ & $\begin{array}{r}\text { Minor axis } \\
\text { length }(\mathrm{km})\end{array}$ & $\begin{array}{r}\text { Major axis } \\
\text { direction }\left(^{\circ}\right)\end{array}$ & $\begin{array}{r}\text { Major axis } \\
\text { length }(\mathrm{km})\end{array}$ & $\begin{array}{r}\text { Minor axis } \\
\text { length }(\mathrm{km})\end{array}$ \\
\hline $4 \mathrm{~h}$ & $36^{\circ}$ & 229 & 61 & $42^{\circ}$ & 107 & 56 & $19^{\circ}$ & 100 & 72 \\
\hline $12 \mathrm{~h}$ & $29^{\circ}$ & 253 & 65 & $40^{\circ}$ & 97 & 58 & $40^{\circ}$ & 87 & 62 \\
\hline $24 \mathrm{~h}$ & $25^{\circ}$ & 269 & 71 & $38^{\circ}$ & 85 & 55 & $39^{\circ}$ & 92 & 77 \\
\hline $36 \mathrm{~h}$ & $27^{\circ}$ & 386 & 65 & $35^{\circ}$ & 86 & 55 & $43^{\circ}$ & 83 & 79 \\
\hline
\end{tabular}


Table 4. Directions and semilengths of the axes of scale of fluctuation (SoF).

\begin{tabular}{|c|c|c|c|c|c|c|c|c|c|}
\hline \multirow[t]{2}{*}{ Duration } & \multicolumn{3}{|c|}{ 5-7 Jun 2008 storm } & \multicolumn{3}{|c|}{ 17-21 Aug 2005 storm } & \multicolumn{3}{|c|}{ 22-24 Jul 1994 storm } \\
\hline & $\begin{array}{r}\text { Major axis } \\
\text { direction }\left({ }^{\circ}\right)\end{array}$ & $\begin{array}{r}\text { Semilengths } \\
\text { of the major } \\
\text { axes }(\mathrm{km})\end{array}$ & $\begin{array}{r}\text { Semilengths } \\
\text { of the minor } \\
\text { axes }(\mathrm{km})\end{array}$ & $\begin{array}{r}\text { Major axis } \\
\text { direction }\left({ }^{\circ}\right)\end{array}$ & $\begin{array}{r}\text { Semilengths } \\
\text { of the major } \\
\text { axes }(\mathrm{km})\end{array}$ & $\begin{array}{r}\text { Semilengths } \\
\text { of the minor } \\
\text { axes }(\mathrm{km})\end{array}$ & $\begin{array}{r}\text { Major axis } \\
\text { direction }\left({ }^{\circ}\right)\end{array}$ & $\begin{array}{r}\text { Semilengths } \\
\text { of the major } \\
\text { axes }(\mathrm{km})\end{array}$ & $\begin{array}{r}\text { Semilengths } \\
\text { of the minor } \\
\text { axes }(\mathrm{km})\end{array}$ \\
\hline $4 \mathrm{~h}$ & $-18^{\circ}$ & 31 & 9 & $-3^{\circ}$ & 14 & 5 & $8^{\circ}$ & 10 & 7 \\
\hline $12 \mathrm{~h}$ & $-7^{\circ}$ & 17 & 7 & $38^{\circ}$ & 37 & 7 & $21^{\circ}$ & 9 & 6 \\
\hline $24 \mathrm{~h}$ & $-36^{\circ}$ & 12 & 8 & $33^{\circ}$ & 23 & 7 & $4^{\circ}$ & 9 & 6 \\
\hline $36 \mathrm{~h}$ & $-79^{\circ}$ & 18 & 6 & $36^{\circ}$ & 24 & 7 & $9^{\circ}$ & 7 & 6 \\
\hline
\end{tabular}

(a)

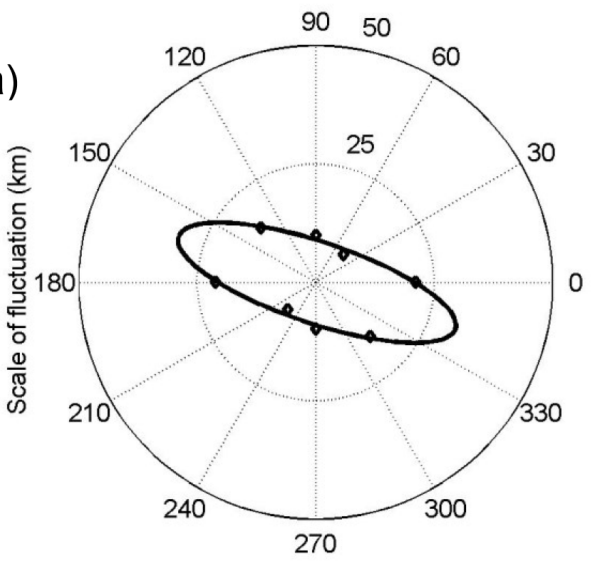

(c)

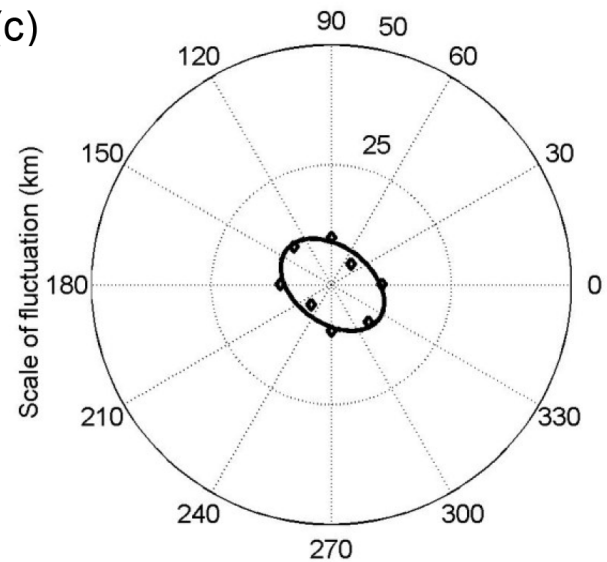

(b)

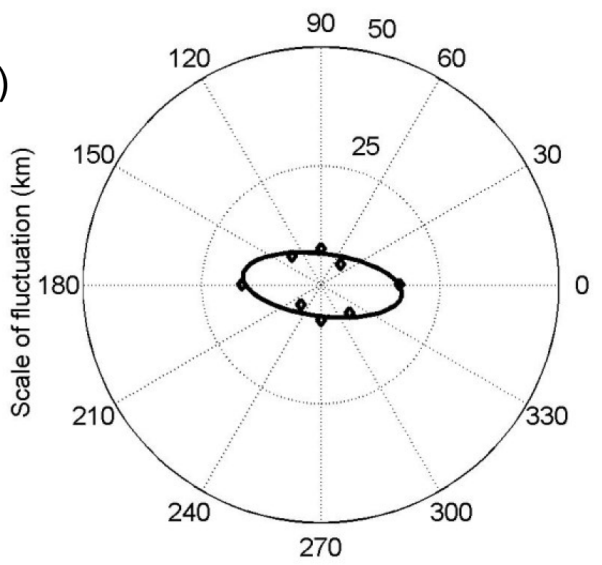

(d)

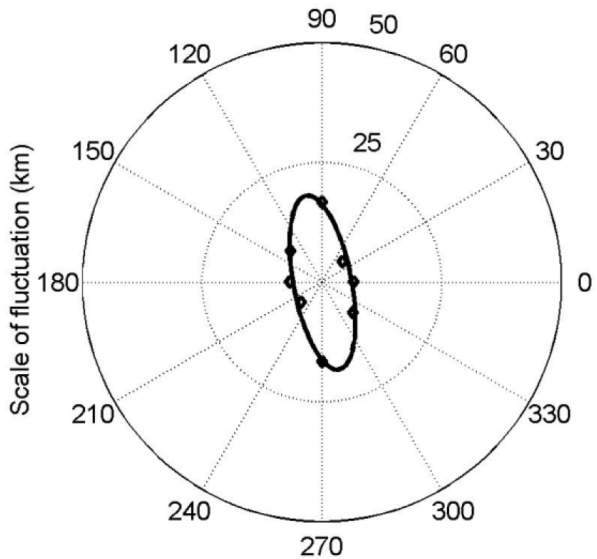

Figure 13. Scale of fluctuation values and ellipse-fitting curves for the 5-7 June 2008 storm: (a) maximum rolling $4 \mathrm{~h}$ rainfall, (b) maximum rolling $12 \mathrm{~h}$ rainfall, (c) maximum rolling $24 \mathrm{~h}$ rainfall, and (d) maximum rolling $36 \mathrm{~h}$ rainfall.

nor axes can be calculated as those of the ellipse with rainfall value approaching zero. The directions and lengths of the trend surfaces are summarized in Table 3 . The major and minor axes of the trend surfaces are determined by least-squares fitting of the original rainfall data. For an individual storm event, the maximum points of the trend surfaces are inside a relatively small range of $40 \mathrm{~km}$. The storm center of each event on the trend surface agrees with the reality. The storm centers of the 7 June 2008 storm, the 17-21 August 2005 storm and the 23 July 1994 storm are at west Lantau Island, Sha Tin, and Tai Mo Shan, respectively. The major directions of the spatial forms are between 19 and $43^{\circ}$ in the anticlockwise direction.

\subsection{Determination of the scale of fluctuation of precipitation residuals}

A classical way to characterize the spatial correlation is through an autocorrelation function (ACF), $\rho(h)$ (Fenton and 

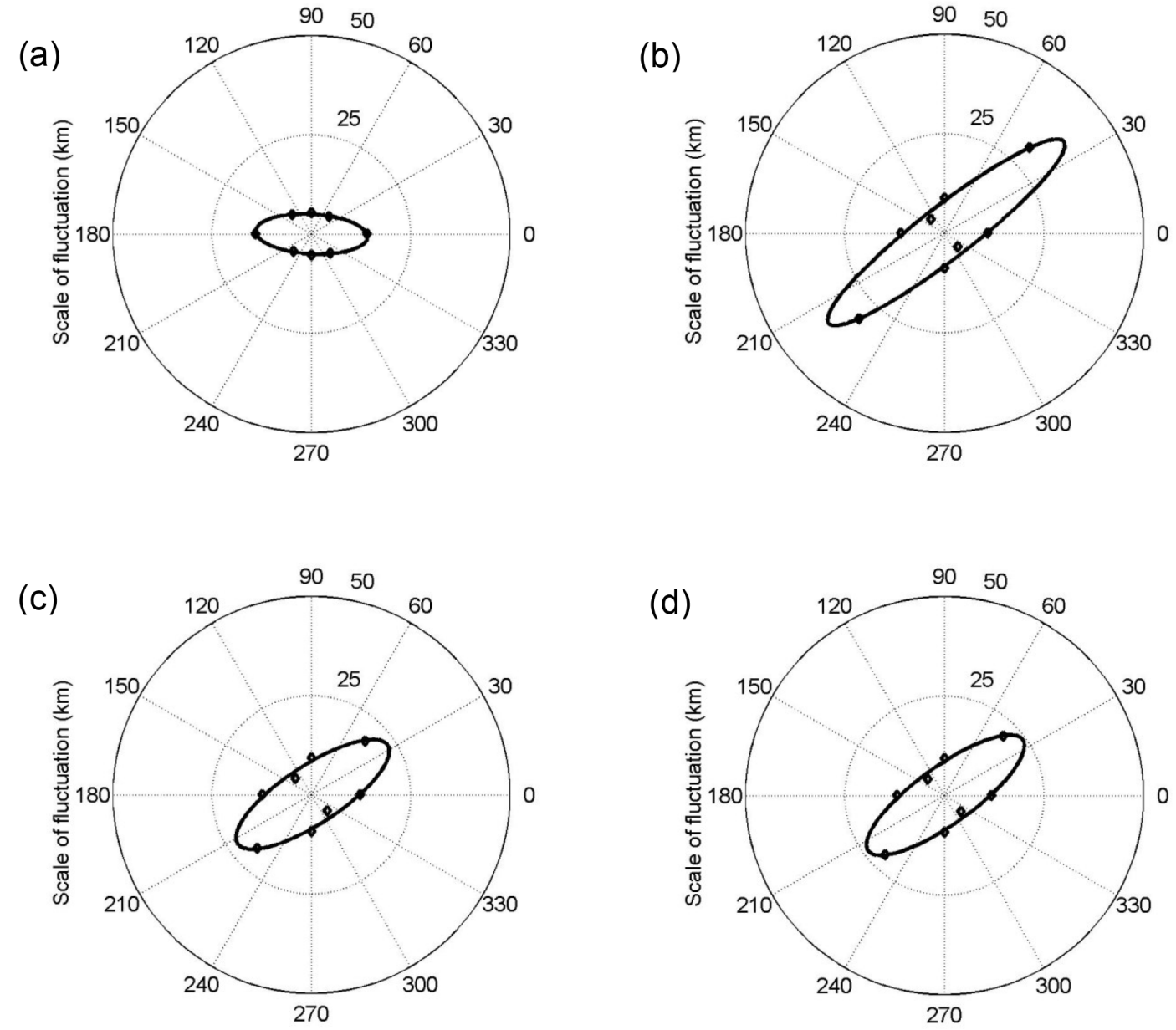

Figure 14. Scale of fluctuation values and ellipse-fitting curves for the 17-21 August 2005 storm: (a) maximum rolling $4 \mathrm{~h}$ rainfall, (b) maximum rolling $12 \mathrm{~h}$ rainfall, (c) maximum rolling $24 \mathrm{~h}$ rainfall, and (d) maximum rolling $36 \mathrm{~h}$ rainfall.

Griffiths, 2008; Foresti and Seed, 2014). The autocorrelation describes the correlation between values of a same series. The autocorrelation $r(k)$ for lags $k=0,1, \ldots, m$, where $m$ is the maximum number of lags, is evaluated by the following equation:

$r_{k}=\frac{\frac{1}{(N-k-1)} \sum_{i=1}^{N-k}\left(z_{i}-\bar{z}\right)\left(z_{i+k}-\bar{z}\right)}{\frac{1}{(N-1)} \sum_{i=1}^{N-k}\left(z_{i}-\bar{z}\right)^{2}}$,

where $z_{i}$ and $z_{i+k}$ are the detrended storm depths at locations $i$ and $i+k$, respectively; $N$ is the total number of the residuals; and $\bar{z}$ is the mean value of the residuals.

In order to assess the autocorrelation structure of the detrended storm amounts, it is necessary to perform regression analysis to fit the ACF. Among many correlation structures, the single exponential structure is the most common:

$\rho(h)=\exp (-2 h / \theta)$ where $h$ is the separation distance or lag; $\theta$ is the scale of fluctuation (SoF). The correlation $\rho(h)$ decays exponentially with separation distance $h$. The negative autocorrelation coefficient will not be evaluated. The values of $\theta$ can be obtained accordingly. Within the scale of fluctuation, the rainfall property is strongly correlated. A smaller scale of fluctuation indicates more rapid fluctuations of the mean.

The scale of fluctuation is evaluated in the directions of $\mathrm{N} 0, \mathrm{~N} 45, \mathrm{~N} \mathrm{90}$, and $\mathrm{N} 135^{\circ} \mathrm{E}$ for each storm. The values of SoF are fitted by an ellipse using least-squares fitting. The values of SoF and the fitting curves are shown in Figs. 1315. Greater SoF values indicate smaller variability. The major direction can be recognized as the direction of maximum continuity.

The direction and major and minor scales of fluctuation are summarized in Table 4. The SoF values of the rainfall residuals are between 6 and $37 \mathrm{~km}$. Regardless of the variations of the principal axis direction, the minor-axis lengths of the SoF values remain around $7 \mathrm{~km}$ (Table 4). 

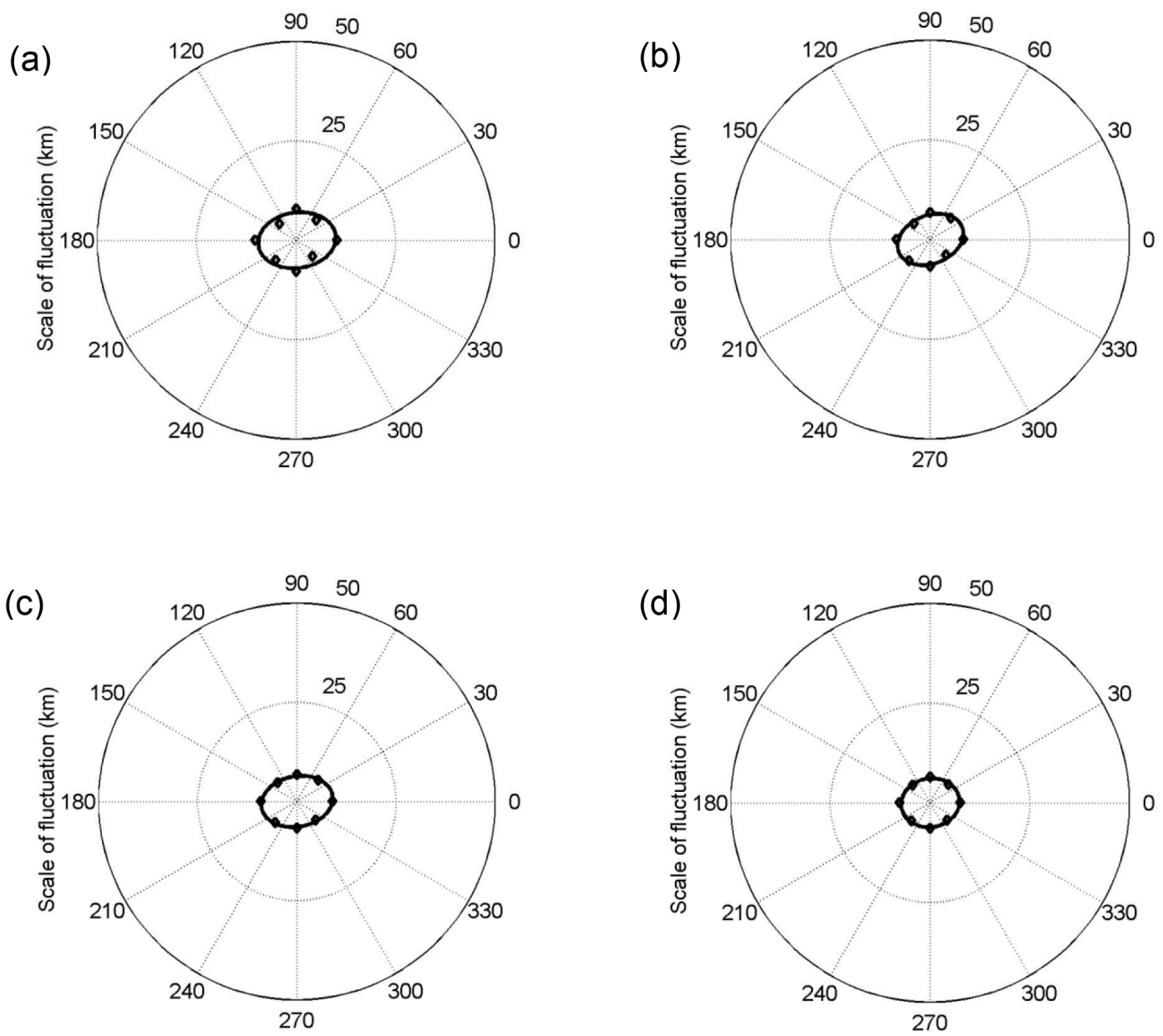

Figure 15. Scale of fluctuation values and ellipse-fitting curves for the 22-24 July 1994 storm: (a) maximum rolling $4 \mathrm{~h}$ rainfall, (b) maximum rolling $12 \mathrm{~h}$ rainfall, (c) maximum rolling $24 \mathrm{~h}$ rainfall, and (d) maximum rolling $36 \mathrm{~h}$ rainfall.

\section{Spatial description of rainstorms}

\subsection{Geometric spatial form and correlation structure}

Though rainfall varies over space, the rainfall amount of a particular storm in terms of maximum rolling rainfall can be fitted by a polynomial function. The spatial form of the rainfall amount can be represented by a rotated ellipsoid with only one center. Such an artificial spatial form may exhibit geometrical regularity. For each storm, the trend surfaces in different durations show good consistency in the shape parameters in terms of the peak point, long-axis direction and axis length. The peak points on the trend surfaces of the three storms are located in a relatively small range. The long-axis directions of the spatial forms of each event in different durations almost remain unchanged between 19 and $43^{\circ}$. The lengths of the major and minor axes for an individual storm show consistency. The 5-7 June 2008 storm has the largest impact area, as indicated by larger axis lengths among the three rainstorms according to the results in Table 3.
With respect to the instantaneous rainfall processes shown in Figs. 9-11, the rainfall distributions in terms of maximum rolling rainfall are quite consistent to the heaviest rainfall process in each storm event. The rainfall distributions are strongly affected by the storm humidity transportation and are so uneven that the entire area should not be described as a single site. The locations of the storm centers determine the general trend of the areal rainfall distribution. The polynomial trend surfaces are effective for representing large rainstorm distributions in terms of maximum rolling rainfall.

The spatial connectivity can be assessed by the SoF values. A smaller scale of fluctuation indicates more rapid fluctuations of the mean. According to Figs. 13-15, all of the SoF values are within $30 \mathrm{~km}$, though the semilengths of the major axes of fitting curves are larger. Hence a reasonable upper threshold for the spatial connectivity is estimated to be $30 \mathrm{~km}$. However, the lengths of the minor axis of the SoF values are between 5 and $8 \mathrm{~km}$. The lower limit of the SoF values of the rainfall data is considered to be $5 \mathrm{~km}$. Therefore, the rainfall amount in Hong Kong is observed to be strongly 

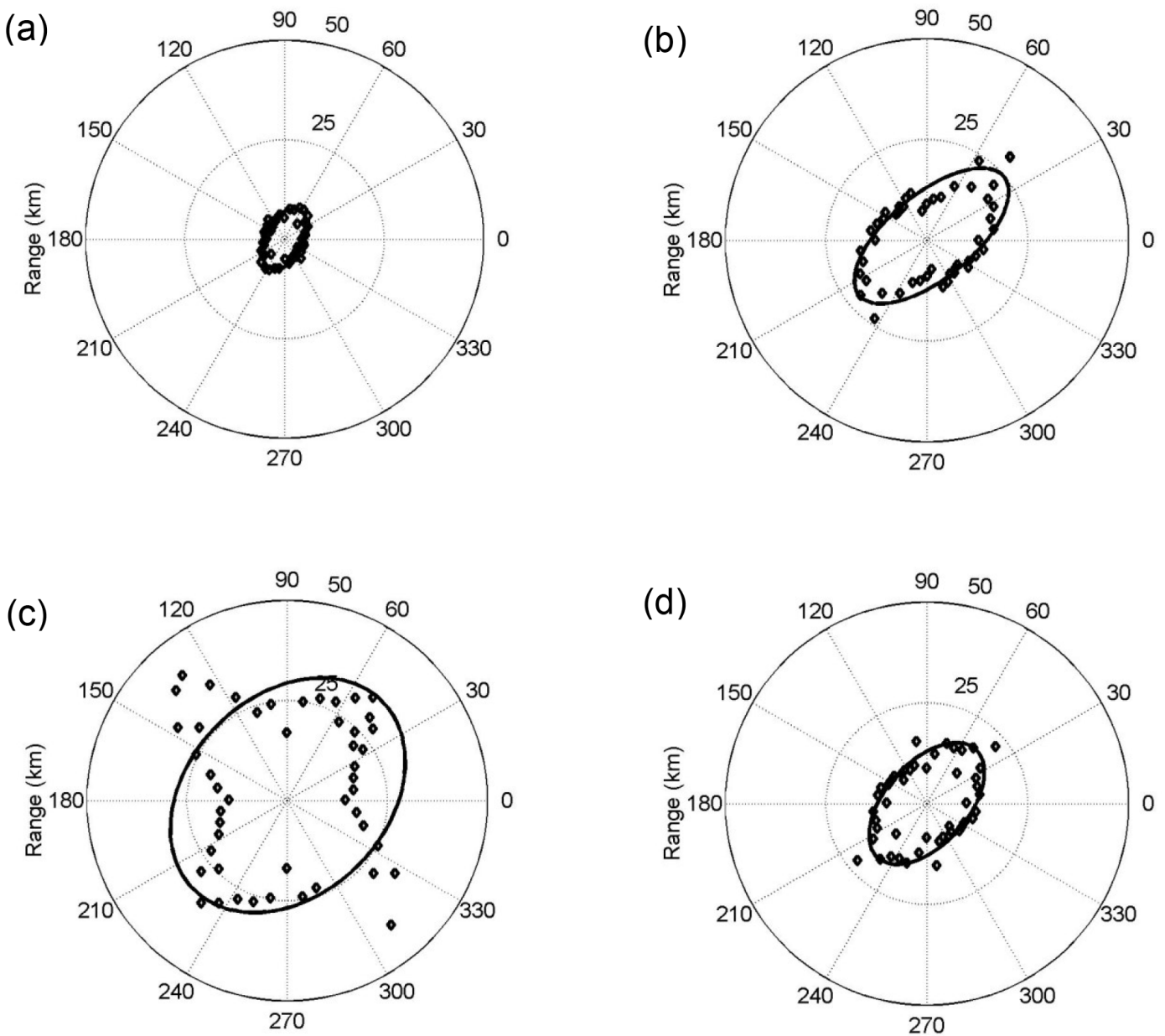

Figure 16. Range values for (a) the 18 May 2007 storm (16:30 LT), (b) the 19 May 2007 storm (16:00 LT), (c) the 19 April 2008 storm (20:00 LT), and (d) the 15 September 2009 storm (15:00 LT; modified from Liu, 2013).

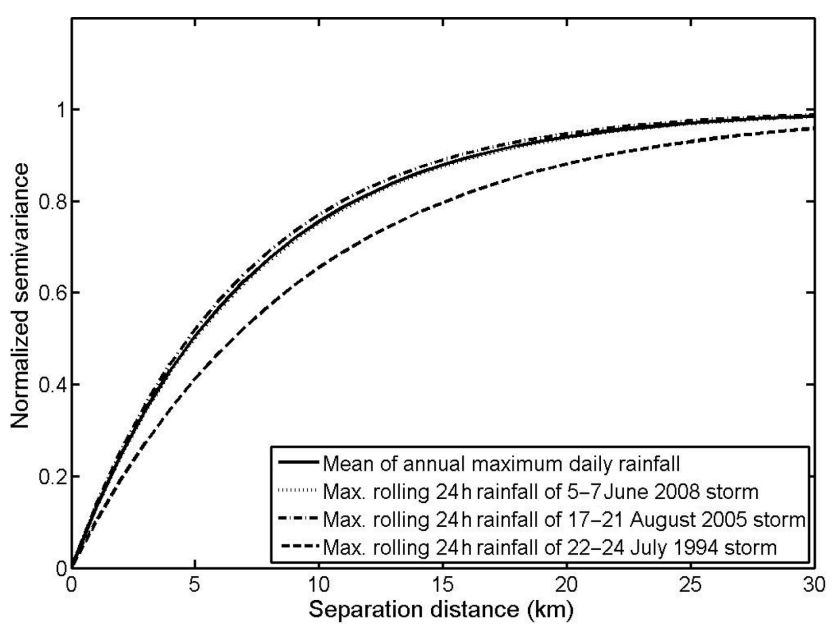

Figure 17. Normalized semivariances of the maximum rolling $24 \mathrm{~h}$ rainfall of the three storms and the mean annual maximum daily rainfall in Hong Kong. spatially correlated within $5 \mathrm{~km}$, whose spatial continuity is smaller than $30 \mathrm{~km}$.

\subsection{Comparison with the spatial structures of ordinary rainfall events}

Besides the three large rainstorm events in this paper, ordinary rainstorm events in Hong Kong have also been studied (Liu, 2013; AECOM and Lin, 2015). Liu (2013) proposed a framework for analyzing dynamic time-space evolution of rain fields in her thesis. Four rain events were chosen to illustrate the spatial structure of rainfall in Hong Kong: the 18 and 19 May 2007, 19 April 2008, and 15 September 2009 rain events in Hong Kong. The 19 April 2008 rainstorm event was under a combined effect of Typhoon Neoguri and a northeast monsoon, while the other three rainstorms were results of tropical depressions. The total rainfall amounts during the four rainfall events on 18 and 19 May 2007, 19 April 2008, and 15 September 2009 were 67.0 and 99.6, 157.9, and $130.3 \mathrm{~mm}$, respectively. The spatial structures of the four 
rain events indicated by variogram ranges corresponding to the peak rainfall intensity ( 6 min resolution) are plotted in Fig. 16. According to the results from ellipse fitting, the major principal directions of all the tropical depression storms (i.e., on 18 and 19 May 2007 and 15 September 2009) are around $\mathrm{N} 45^{\circ} \mathrm{E}$. The lengths of the principal axis of the tropical depression storms are within $30 \mathrm{~km}$, while that of the 19 April 2008 storm is $40.8 \mathrm{~km}$. The correlation structures of the instantaneous rain processes are consistent with those of the three large storms as illustrated in Sect. 5.1.

The spatial structure of annual maximum daily rainfall using the variogram model provides additional information for generating design storms from another point of view. According to the study conducted by Jiang and Tung (2014), the spatial variability represented by a variogram is used to establish the rainfall depth-duration-frequency relationships. By normalizing the indicator semivariogram by the variance of the indicator data, the normalized semivariances of the mean annual maximum daily rainfall and the maximum rolling $24 \mathrm{~h}$ rainfall of the three storms are shown in Fig. 17. Based on the samples and the fitted exponential variogram model, the range of the mean of annual maximum daily rainfall is $7.1 \mathrm{~km}$, which is close to the omnidirectional range values of the maximum rolling $24 \mathrm{~h}$ rainfall for the storms, particularly those for the 2008 storm and the 2005 storm. Thus, given a large storm whose spatial distribution is relatively smooth, the range value will be close to that of the annual maximum daily rainfall. The spatial structures of the three severe storms and the four ordinary rainfall events do not differ significantly.

With aspect to the local terrain impacts, the major directions of both the three large rainstorms and the ordinary rainfall events are all consistent with the mountain range alignment in Hong Kong (Fig. 3). However, the severe storms are highly uncertain and it is difficult to ascertain and predict the future precipitation and extreme rainfall. Lu et al. (2013), Lu and Lall (2016), and Najibi et al. (2017) suggest a potential direction to further study the associated atmospheric circulation with moisture transport that has improved the predictability of extreme rainfall and flooding in various regions, including western Europe and the Midwest and northeast of the United States. The spatial structure found in this study also indicates that there might be a link between the distribution and the convergence of the moist air into the Hong Kong region.

\section{Conclusions}

A random rain-field model has been proposed to study the spatial characteristics of three large landslide-triggering rainstorms in Hong Kong. The cumulative rainfall depths in terms of maximum rolling rainfall in different durations are of particular importance for landslide studies and are taken as random variables in this study. Based on the study, the following conclusions can be drawn:

1. The amounts of maximum rolling rainfall in different durations share a dominating spatial structure that can be represented by a rotated ellipsoid surface established using the ordinary least-squares method. The shapes change slightly in different durations for a particular storm.

2. The major principal directions of the surface trends of the three rain storms are between $19^{\circ}\left(\mathrm{N} 71^{\circ} \mathrm{E}\right)$ and $43^{\circ}\left(\mathrm{N} 47^{\circ} \mathrm{E}\right)$, and the principal major and minor axis lengths are 83-386 and 55-79 km, respectively.

3. The spatial connectivity of large storms in Hong Kong is estimated to be between 5 and $30 \mathrm{~km}$. The rainfall amounts in the three large storms are observed to be strongly correlated within $5 \mathrm{~km}$ and likely to be connected within $30 \mathrm{~km}$.

4. To verify the rationality and reliability of the spatial structures of large rainstorms, the spatial characteristics of four ordinary rainfall events are also studied. The spatial structures of the three large rainstorms are similar with those of the ordinary rainfall events and consistent with the mountain range alignment in Hong Kong.

Data availability. The key rainfall data for this research are available at http://cezhangl.people.ust.hk/Totalrainfall.xlsx.

Competing interests. The authors declare that they have no conflict of interest.

Acknowledgements. The authors would like to thank the Geotechnical Engineering Office (GEO) of the Civil Engineering and Development Department (CEDD) for providing the rainfall data described in this paper. This research is supported by the Research Grants Council of the Hong Kong SAR (nos. C6012-15G and 16202716).

Edited by: Thomas Kjeldsen

Reviewed by: two anonymous referees

\section{References}

AECOM and Lin, B.: $24 \mathrm{~h}$ Probable Maximum Precipitation Updating Study. GEO Report No. 314, Geotechnical Engineering Office, Hong Kong, 2015.

Bacchi, B. and Kottegoda, N.: Identification and calibration of spatial correlation patterns of rainfall, J. Hydrol., 165, 311-348, 1995. 
Barancourt, C., Creutin, J. D., and Rivoirard, J.: A method for delineating and estimating rainfall fields, Water Resour. Res., 28, 1133-1144, 1992.

Bouvier, C., Cisneros, L., Dominguez, R., Laborde, J. P., and Lebel, T.: Generating rainfall fields using principal components (PC) decomposition of the covariance matrix: a case study in Mexico City, J. Hydrol., 278, 107-120, 2003.

CEDD: Management of Natural Terrain Landslide Risk, Information Note 03/2008, Geotechnical Engineering Office, Civil Engineering and Development Department, Hong Kong, 2008.

CEDD: Landslide Potential Index. Information Note 03/2009, Geotechnical Engineering Office, Civil Engineering and Development Department, Hong Kong, 2009.

Chan, W. L.: Hong Kong Rainfall and Landslides in 1994, GEO report No. 54, Geotechnical Engineering Office, Hong Kong, 1995.

Chang, W. L. and Hui, T. W.: Probable Maximum Precipitation for Hong Kong, Reprint 482, Hong Kong Observatory, Hong Kong, 2001

Dai, F. C. and Lee, C. F.: Frequency-volume relation and prediction of rainfall-induced landslides, Eng. Geol., 59, 253-266, 2001.

Dasaka, S. M. and Zhang, L. M.: Spatial variability of in situ weathered soil, Géotechnique, 62, 375-384, 2012.

de Luca, D. L.: Analysis and modelling of rainfall fields at different resolutions in southern Italy, Hydrolog. Sci. J., 59, 1536-1558, 2014

Fenton, G. A. and Griffiths, D. V.: Risk Assessment in Geotechnical Engineering, John Wiley and Sons, Inc., Hoboken, New Jersey, 2008.

Foresti, L. and Seed, A.: The effect of flow and orography on the spatial distribution of the very short-term predictability of rainfall from composite radar images, Hydrol. Earth Syst. Sci., 18, 46714686, https://doi.org/10.5194/hess-18-4671-2014, 2014.

Gao, L., Zhang, L. M., Chen, H. X., Shen, P.: Simulating debris flow mobility in urban settings, Eng. Geol., 214, 67-78, 2016.

Gao, L., Zhang, L. M., and Chen, H. X.: Likely scenarios of natural terrain shallow slope failures on Hong Kong Island under extreme storms, Nat. Hazards Rev.,18, B4015001, https://doi.org/10.1061/(ASCE)NH.1527-6996.0000207, 2017.

Grimes, D. I. F. and Pardo-Igúzquiza, E.: Geostatistical analysis of rainfall geographical analysis, Geogr. Anal., 42, 136-160, 2010.

Gyasi-Agyei, Y. and Pegram, G.: Interpolation of daily rainfall networks using simulated radar fields for realistic hydrological modelling of spatial rain field ensembles, J. Hydrol., 519, 777-791, 2014

Jiang, P. and Tung, Y. K.: Incorporating daily rainfalls to derive rainfall DDF relationships at ungauged sites in Hong Kong and quantifying their uncertainty, Stoch. Env. Res. Risk A., 29, 45$62,2014$.

Journel, A. G. and Huijbergts, C. J.: Mining Geostatistics, Academic Press, London, 1978.

King, J. P.: Natural Terrain Landslide Study: Natural Terrain Landslide Inventory, GEO Report No. 74, Geotechnical Engineering Office, Hong Kong, 1999.

Kong, H. S. W. and Ng, A. F. H.: Factual Report on Hong Kong Rainfall and Landslides in 2005, GEO Report No. 223, Geotechnical Engineering Office, Hong Kong, 2006.
Lebel, T., Bastin, G., Obled, C., Creutin, J. D.: On the accuracy of areal rainfall estimation: a case study, Water Resour. Res., 23, 2123-2134, 1987.

Leung, J. K. Y. and Law, T. C.: Kriging analysis on Hong Kong rainfall data, HKIE Transactions, 9, 26-31, 2002.

Li, A. C. O., Lau, J. W. C., Cheung, L. L. K., and Lam, C. L. H.: Review of Landslides in 2008, GEO Report No. 274, Geotechnical Engineering Office, Hong Kong, 2009.

Li, X. Y., Zhang, L. M., and Li, J. H.: Using conditioned random field to characterize the variability of geologic profiles, J. Geotech. Geoenviron., 142, 04015096, https://doi.org/10.1061/(ASCE)GT.1943-5606.0001428, 2015.

Liu, P.: Framework for Analysing Dynamic Time-Space Evolution of Rain-Field, MPhil thesis, The Hong Kong University of Science and Technology, 2013.

Lu, M. and Lall, U.: Tropical Moisture Exports, Extreme Precipitation and Floods in Northeast US, Hydrol. Earth Syst. Sci. Discuss., https://doi.org/10.5194/hess-2016-403, 2016.

Lu, M., Lall, U., Schwartz, A., and Kwon, H.: Precipitation predictability associated with tropical moisture exports and circulation patterns for a major flood in France in 1995, Water Resour. Res., 49, 6381-6392, 2013.

Mascaro, G., Deidda, R., and Hellies, M.: On the nature of rainfall intermittency as revealed by different metrics and sampling approaches, Hydrol. Earth Syst. Sci., 17, 355-369, https://doi.org/10.5194/hess-17-355-2013, 2013.

Maunsell-Fugro Joint Venture: Final Report on Compilation of the Enhanced Natural Terrain Landslide Inventory (ENTLI), Maunsell-Fugro Joint Venture and Geotechnical Engineering Office, Hong Kong, 2007.

Najibi, N., Devineni, N., and Lu, M.: Hydroclimate drivers and atmospheric teleconnections of long duration floods: An application to large reservoirs in the Missouri River Basin, Adv. Water Resour., 100, 153-167, 2017.

Panthou, G., Vischel, T., Lebel, T., Quantin, G., and Molinié, G.: Characterising the space-time structure of rainfall in the Sahel with a view to estimating IDAF curves, Hydrol. Earth Syst. Sci., 18, 5093-5107, https://doi.org/10.5194/hess-18-5093-2014, 2014.

Rodríguez-Iturbe, I., Cox, D. R., and Eagleson, P. S.: January. Spatial modelling of total storm rainfall, P. Roy. Soc. A-Math. Phys., 403, 27-50, 1986.

Tam, K. H. Au, C. H., and Chang, W. L.: The Severe Rainstorms on 22-24 July 1994 in Hong Kong, Reprint 256, Hong Kong Observatory, Hong Kong, 1995.

Vanmarcke, E. H.: Probability modelling of soil profiles, J. Geotech. Eng.-ASCE, 103, 1227-1246, 1977.

World Meteorological Organization: Manual on Estimation of Probable Maximum Precipitation (PMP), WMO-No.1045, Geneva, 2009.

Zawadzki, I. I.: Statistical properties of precipitation patterns, J. Appl. Meteorol., 12, 459-472, 1973. 